
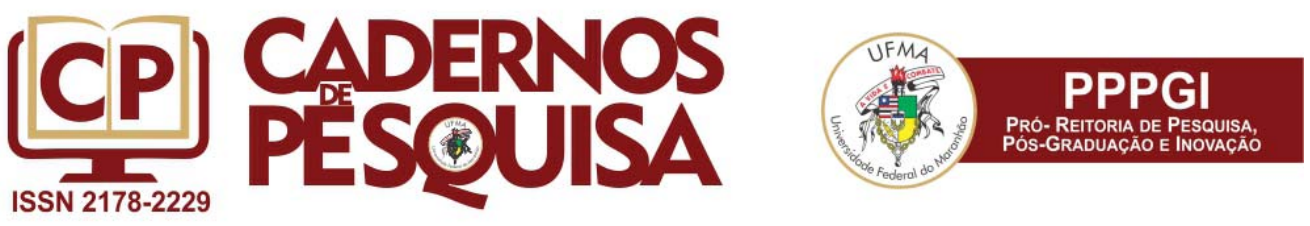

\title{
AS REDES SOCIAIS NA FORMAÇÃO DE COMUNIDADES DE APRENDIZAGEM EM NUTRIÇÃO INFANTIL E BLW
}
THE SOCIAL NETWORKS IN THE FORMATION OF LEARNING COMMUNITIES ON CHILDREN'S NUTRITION AND BLW

\section{LAS REDES SOCIALES EN LA FORMACIÓN DE COMUNIDADES DE APRENDIZAJE SOBRE NUTRICIÓN INFANTIL Y BLW}

\author{
Gabriela Eyng Possolli \\ Professora Doutora do programa de pós-graduação em \\ Ensino nas Ciências da Saúde da Faculdades Pequeno Príncipe (FPP) \\ Paraná-PR, Brasil \\ gabriela.possolli@fpp.edu.br \\ Renata Bragato Futagami \\ Professora do curso de Medicina da \\ Universidade Federal do Paraná (UFPR) \\ Paraná-PR, Brasil \\ re_futagami@hotmail.com
}

\begin{abstract}
Resumo
O artigo teve como objetivo mapear os conteúdos em redes sociais sobre a nutrição infantil e BLW (Baby Led Weaning), visando compreender como se organizam enquanto comunidades de aprendizagem. A metodologia utilizada foi do tipo explicativa de abordagem mista. Na coleta de dados, foram analisadas 6 comunidades do Facebook e 4 perfis do Instagram com representatividade na temática nutrição infantil. Resultados: $\mathrm{O}$ quantitativo de postagens por mídia nas 10 comunidades ocorreu da seguinte forma: Texto 6.543 postagens (63\%); Imagem 3.250 postagens (31\%); Vídeo 647 postagens (6\%). O Instagram apresentou mais postagens de imagens do que textos; ao contrário das comunidades de aprendizagem do Facebook que produzem maior quantidade de conhecimento por meio de textos narrativos. Notou-se que os perfis do Instagram possuem número maior de seguidores em relação aos grupos do Facebook, porém a quantidade de postagens é menor, o que condiz com o estilo de utilização dessas redes sociais. O Facebook, por formar grupos, apresenta maior interatividade com os usuários, ao contrário do Instagram que apresenta uma rede social mais passiva e com a maior parte dos usuários observando e curtindo postagens. As comunidades de aprendizagem em redes sociais demonstraram que são espaços efetivos para apoio e construção coletiva de saberes com grande potencial de expansão nas áreas de educação e de saúde. Essa aprendizagem se dá, principalmente. por meio de trocas colaborativas e construção interativa de conhecimento.
\end{abstract}

Palavras-chave: Redes sociais. Nutrição infantil. Comunidades virtuais de aprendizagem.

\begin{abstract}
This article aimed to map the contents on communities in social networks about the children's nutrition and BLW (Baby Led Weaning), aiming to understand how are organized while communities of learning. The methodology used was of the explanatory type and mixed approach. The data collection of the research was carried out online and 6 communities of Facebook and 4 Instagram profiles were selected with great representativeness in the theme of children's nutrition and BLW. Results: The number of postings per media in the 10 communities occurred as follows: Text 6.543 posts (63\%); Image 3,250 posts (31\%); Video 647 posts $(6 \%)$. Instagram presented more pictures posts than texts unlike Facebook's learning communities, that produce more knowledge through narrative texts. It was noted that Instagram profiles have more followers in relation to Facebook groups, but the number of posts is lower, which is consistent with the style of use of these social networks. The Facebook for to form groups has more interactivity with users,
\end{abstract}

Artigo recebido em agosto 2017. Aprovado em fevereiro de 2018.

Cad. Pesq., São Luís, v. 25, n. 2, abr./jun. 2018. 
opposite of Instagram that presents a more passive social network and with the majority of users observing and enjoying postings. In relation to the objective of the research that was to map the content present in social networks on child nutrition and BLW. The learning communities in social networks have proved to be effective spaces for support and collective construction of knowledge with great potential for expansion in the areas of education and health.

Keywords: Social networks. Children's nutrition. Virtual learning communities.

\section{Resumen}

El artículo tuvo como objetivo mapear los contenidos en redes sociales sobre la nutrición infantil y BLW (Baby Led Weaning), buscando comprender cómo se organizan como comunidades de aprendizaje. La metodología utilizada fue del tipo explicativo de abordaje mixto. En la recolección de datos se analizaron 6 comunidades de Facebook y 4 perfiles del Instagram con representatividad en la temática nutrición infantil. Resultados: El cuantitativo de las entradas por medios en las 10 comunidades se produjo de la siguiente manera: Texto 6.543 postes (63\%); Figura 3.250 entradas (31\%); Vídeo 647 entradas (6\%). El Instagram presentó más mensajes de imágenes que textos a diferencia de las comunidades de aprendizaje de Facebook, que producen mayor cantidad de conocimiento a través de textos narrativos. Se ha notado que los perfiles del Instagram tienen un número mayor de seguidores en relación a los grupos de Facebook, pero la cantidad de entradas es menor, lo que concuerda con el estilo de utilización de esas redes sociales. Facebook por formar grupos presenta mayor interactividad con los usuarios, a diferencia de Instagram que presenta una red social más pasiva y con la mayoría de los usuarios observando y disfrutando de los posts. Las comunidades de aprendizaje en redes sociales demostraron ser espacios efectivos para apoyo y construcción colectiva de saberes con gran potencial de expansión en el área de educación y de salud. Este aprendizaje se da principalmente a través de intercambios colaborativos y construcción interactiva de conocimiento.

Palabras clave: Redes sociales. Nutrición infantil. Comunidades virtuales de aprendizaje.

\section{INTRODUÇÃO}

A disseminação da cibercultura com o estrondoso avanço do desenvolvimento tecnológico na última década teve impacto significativo nas comunidades, nas percepções sobre o mundo e na busca de conhecimentos. Os ambientes virtuais se tornaram locais ideais para a integração de conteúdos e de pessoas com os mesmos objetivos de interesse. Grupos sociais com interesses em comum surgem por meio da internet nas redes sociais, possibilitando uma interação cada vez mais ativa, criando laços comunitários. O ciberespaço possibilita que a informação produzida seja armazenada e disseminada globalmente, facilitando o processo de circulação e incorporação de informações, além de colaborar com a organização de ações em rede. Esses espaços interativos da internet têm se tornado essenciais para a educação com vistas à promoção da saúde.

A possibilidade de acesso on-line às informações muda a dinâmica da relação médico-paciente. A forma de introdução alimentar chamada Baby Led Weaning (BLW) passou por uma ordem inversa de propagação, uma vez que teve uma rápida disseminação, através das redes sociais e os familiares acabaram trazendo essa forma de alimentação complementar para os consultórios médicos. É pequena a quantidade de livros impressos sobre esse assunto, mas extensa a quantidade de informações encontradas on-line, em eventos e entrevistas sobre nutrição infantil.

O BLW estimula a introdução alimentar conduzida pelo próprio bebê. Criado pela médica britânica Gill Rapley, vem ganhando admiradores em todo o mundo, principalmente pelos seus efeitos benéficos no desenvolvimento da criança, como o estímulo a refeições familiares em conjunto, hábitos alimentares saudáveis e vantagens no desenvolvimento motor (CAMERON; HEATH; TAYLOR, 2012).

Redes sociais impulsionando a formação de comunidades de aprendizagem sobre alimentação infantil é um assunto atual e pouco estudado (CAMERON; HEATH; TAYLOR, 2012). Nesse contexto, a presente pesquisa propõe uma reflexão sobre os avanços educativos da utilização das redes sociais com conteúdos relacionados à saúde na nutrição 
infantil. A problematização desta pesquisa busca saber: Comunidades de aprendizagem em redes sociais favorecem a construção de conhecimentos sobre nutrição infantil?

O objetivo geral da pesquisa foi: Mapear os conteúdos presentes em comunidades de aprendizagem em redes sociais sobre a nutrição infantil e BLW. A pesquisa exploratória, de abordagem mista e com observação participantes, teve coleta de dados on-line em comunidades do Facebook e Instagram. Para mapear as comunidades e perfis mais relevantes, optou-se por escolher os que continham maior número de participantes e comunidades, que pesquisadores conheciam e que abordavam os temas: pediatria, nutrição infantil e BLW.

\section{INTERNET NA SOCIEDADE CONTEMPORÂNEA, A EDUCAÇÃO E A SAÚDE}

Na presente era digital, a tecnologia muda as formas de pensamento, os costumes e hábitos da sociedade. A interação amplia-se e permite que todos se relacionem com desconhecidos por meio da ciberexistência e gera novas formas de relações sociais adaptadas ao espaço e ao tempo virtual e à possibilidade de construção de novas identidades. É a comunicação mediada por computador que dá a identidade na cibercultura (SILVA, 2004). A rede surge, então, como um espaço democrático, em que todos têm igualdade de oportunidades, independentemente de questões de gênero, sexo, classe social ou etnia.

Esses meios interferem na vida social e acabam modificando a percepção que as pessoas têm do espaço-tempo, vindo a constituir novas tendências na vida social que, por sua vez, convivem ou transformam hábitos, como, por exemplo, a educação à distância, home-office, e-commerce, comunidades virtuais, possibilidade de armazenamento de filmes ou músicas, serviços públicos on-line, entre outros (MONTARDO, 2005). A cibercultura é a origem das comunidades virtuais que, assim como nas comunidades sociais não virtuais, necessitam de regras de conduta que deverão ser respeitadas. Assim surge o termo "netiqueta" que se refere à ética na Internet. Funcionam como um conjunto de regras, virtualmente disseminadas que tentam estabelecer um padrão de comportamento aos participantes (SILVA, 2004).

A evolução da Internet provocou reestruturação de relações sociais e na construção de conhecimentos em âmbito mundial. Castro (2006) descreve três processos básicos de implicação na ciência: pesquisa, circulação e incorporação do conhecimento. $O$ ciberespaço possibilita que a informação produzida seja armazenada e disseminada globalmente, facilitando a circulação e incorporação de informações, além de colaborar com a organização de ações conjuntas em rede. De tal forma que, se rompem barreiras de tempo e espaço e ocorre uma integração entre conhecimentos locais e globais. Não foi diferente na área de saúde, em que a utilização de novas tecnologias levou à disseminação do conhecimento científico de forma vertiginosa e global.

Santos (2007) afirma que espaços interativos da internet e as comunidades virtuais são essenciais para a educação informal e para a promoção da saúde. A educação participativa on-line compreende um fenômeno adaptado às necessidades de um grupo, sem estabelecer um plano prévio no qual os participantes se organizam e controlam todo o processo de aprendizagem.

Com essa revolução, surge o conceito de e-health que se refere às atividades que usam tecnologias digitais em saúde. A internet se tornou um veículo de ações do governo, ONGs, profissionais de saúde e empresas em educação e saúde. Para Canavilhas (2005), no âmbito da saúde, a comunicação desenvolve-se em duas linhas: profissionais-profissionais e profissionais-usuários dos serviços. A busca por informação em saúde na rede, a participação em bate-papos virtuais ou grupos de apoio, envio de e-mails para serviços de saúde, são formas de comunicação interativa em saúde, que, segundo Soares (2004, p. 5), é o termo que se refere à "interação de um indivíduo com ou por meio de um dispositivo eletrônico ou tecnologia de comunicação 
para acessar ou transmitir informação de saúde ou receber ou prover orientação e apoio sobre um assunto relativo à saúde."

\subsection{As redes sociais Facebook e Instagram}

Bruno (2014) afirma que os processos educativos devem ser compreendidos de uma forma aberta e flexível. A educação participativa compreende um fenômeno adaptado às necessidades de um grupo, sem estabelecer um plano prévio em que os participantes se organizam e controlam todo o processo de aprendizagem.

As redes sociais tiveram sua explosão após o desenvolvimento da Web 2.0. Dentro da temática desta pesquisa, pode-se usar a classificação de McLawhorn et al. (2016) que distingue as mídias sociais em duas grandes categorias: redes sociais online de propósito geral (Facebook, Twitter, YouTube, etc) e comunidades de saúde virtuais. As redes sociais de propósito geral são as plataformas mais comumente usadas para informações de saúde e as comunidades de saúde virtuais são plataformas mais colaborativas, geralmente construídas em torno de tópicos específicos de saúde, como é o caso do aplicativo "Figure 1" que é popularmente conhecido como o "Instagram dos médicos".

O Facebook é a rede social mais significativa e popular atualmente. De acordo com a estatística, os principais países classificados de acordo com seu número de usuários do Facebook a partir de maio de 2016, são Índia, Estados Unidos e em terceiro lugar o Brasil, que, durante o período medido, teve 90,11 milhões de usuários brasileiros registrados no site de redes sociais. A Índia ultrapassou os Estados Unidos em número de usuários com mais de 195 milhões, enquanto os EUA possuem 191,3 milhões (STATISTA, 2017).

O Facebook, fundado em 2004, em maio de 2016, constou com, aproximadamente, $58 \%$ de toda a população adulta dos EUA, participando nessa rede, sendo que $70 \%$ de seus usuários acessam o site pelo menos uma vez por dia. Aproximadamente 15\% dos médicos utilizam o Facebook para fins profissionais. Em geral, sua utilidade dentro dos cuidados de saúde é reunir comunidades de pacientes com preocupações semelhantes e facilitar a disseminação de informações de médicos para grandes públicos-alvo. Os grupos de Facebook permitem a construção de comunidades on-line, enquanto as páginas são um mecanismo útil para promover compartilhamento de informações (MCLAWHORN et al., 2016).

Lançado em 2010, o Instagram rapidamente se tornou popular e uma das plataformas de redes sociais mais amplamente utilizadas no mundo. No início de 2015 , foi relatado que mais de 200 milhões de usuários em todo o mundo usavam o serviço para compartilhar 70 milhões de fotos por dia. Como um meio visual-locativo, seus usuários produzem dados enquanto dividem suas rotinas diárias com seus smartphones na mão. Como tal, o Instagram se presta como uma fonte de dados sem precedentes para pesquisadores sociais (BOY; UITERMARK, 2016).

\subsection{Redes sociais e aprendizagens em nutrição infantil}

As práticas alimentares na infância devem ser capazes de fornecer alimento com qualidade nutricional para atender às necessidades das crianças e garantir o desenvolvimento de seu potencial. A alimentação adequada na infância contribui para o estabelecimento de hábitos alimentares saudáveis para a vida adulta. A introdução precoce de alimentos inadequados, como: leite de vaca; consistência inapropriada e baixa densidade; contaminação no preparo e armazenamento; oferta de alimentos industrializados; são práticas que aumentam muito o risco de futuras patologias (CAETANO et al., 2012; CARVALHO et al., 2015).

Baby-led-weaning (BLW) é uma forma de introdução alimentar na qual o bebê serve-se com as mãos em vez de usar talheres (CAMERON; HEATH; TAYLOR, 2012). A sigla BLW significa desmame guiado pelo bebê, é utilizado para a adição de alimentos 
sólidos, enquanto a criança continua a mamar. O termo BLW foi introduzido pela médica Gill Rapley, autora de "Baby-Led Weaning: guia essencial para introdução de alimentos sólidos”, publicado de 2008 (D'ANDREA et al., 2016). Sua incidência vem aumentando em comparação à forma convencional de oferta de purês e papas. O BLW é muito popular no Reino Unido e Nova Zelândia, com número vertiginosamente crescente de sites, vídeos, blogs e fóruns sobre o assunto (CAMERON; HEATH; TAYLOR, 2012).

As tecnologias de informação e comunicação introduziram novas formar de interações humanas e estão gerando mudanças na vida profissional, social e educacional das pessoas. Na saúde, segundo Albuquerque (2013), as TICs promovem redes cooperativas a distância, auxiliam em pesquisas, aperfeiçoam treinamentos, proporcionam acesso a bibliotecas virtuais e revistas eletrônicas, vídeos e conferências.

Barcelos, Passerino e Behar (2010) definem as redes sociais como conjunto de elementos como pessoas, grupos e suas conexões, que apresentam estruturas dinâmicas complexas e que geram um conteúdo imaterial e até mesmo material. Grupos sociais com características em comum vêm surgindo por meio da Internet, interagindo cada vez mais de forma ativa e criando elos comunitários. Nesse contexto, aumentam cada vez mais as comunidades virtuais. Sobre comunidades de aprendizagem em redes sociais, Alavarce e Pierin (2011) definem-nas como um ambiente tecnológico no espaço virtual que permite a troca de informações e auxilia no processo de ensino-aprendizagem. Essas informações podem ser apresentadas de várias formas, como: portais, banco de dados, bibliotecas virtuais, cursos a distância ou outros.

Comunidades de aprendizagem podem ser definidas como espaços onde pessoas com interesses em comum em relação à aprendizagem, trocam conhecimentos, experiências em um processo funcional e colaborativo. Comunidades virtuais de aprendizagem (CV) têm os mesmos objetivos, porém ocorrem via recursos da Internet. Barcelos, Passerino e Behar (2010) definem que CV são agregações virtuais que emergem na rede quando indivíduos se engajam em discussões públicas por certo período e com emoções para formar teias de relações pessoais na Internet, com ênfase na participação dos membros.

Comunidades virtuais de interesse (CVI), segundo Abreu (2006), surgem a partir de um interesse específico por um tema. Permite que se obtenha informação atualizada sobre o objeto de interesse a qualquer hora e em qualquer lugar. Seus membros filiamse voluntariamente e podem ou não compartilhar seus pontos de vista ou experiências, sendo um participante ativo ou apenas observador. As CVI têm o objetivo de participar, envolver-se com sentimento de responsabilidade coletiva na busca de melhorias práticas, solução de problemas ou análise de situações. O ambiente virtual das redes sociais permite a interação e a troca entre participantes, o que facilita a aprendizagem. A integração de diversas mídias, linguagens e recursos abre perspectivas para o desenvolvimento de um processo educacional motivador e interativo, incluindo a troca de conhecimentos a respeito de nutrição infantil.

\section{APRESENTAÇÃO E ANÁLISE DE RESULTADOS}

A pesquisa foi explicativa com abordagem mista. Com relação aos objetivos, foram classificados como pesquisa exploratória. Minayo (2007) descreve a abordagem mista como a que trabalha com o universo de crenças, atitudes e valores para descrever, compreender ou explicar certos fenômenos com base em dados quanti-qualitativos. Para o tratamento das informações dos dados coletados, baseou-se também em Minayo.

A coleta de dados da pesquisa de campo foi realizada on-line, considerando perfis e comunidades em redes sociais. Por serem mais interativas e com maior número de participantes, foram escolhidas 6 comunidades do grupo Facebook em que a pesquisadora participava e que familiares relatavam que esses eram os locais onde mais buscavam informações. No Instagram, que é mais baseado em imagens e vídeos com descrições, foram selecionados 4 perfis com contingente considerável de seguidores. Nesta pesquisa, 
realizou-se um mapeamento de Redes sociais, Facebook e Instagram, por meio da análise de 10 perfis com grande representatividade para famílias e profissionais de saúde na temática de nutrição infantil. O mapeamento das redes sociais foi realizado nos meses de janeiro e fevereiro/2017 considerando o período de 6 meses de postagens (setembro de 2016 a fevereiro de 2017), sendo mapeadas nove comunidades virtuais nacionais e uma internacional, perfazendo um total de 10 comunidades.

Foram definidos como critérios de inclusão para participação: aceitar participar da pesquisa mediante a leitura e aceitação do Termo de Consentimento Livre e Esclarecido. O projeto de pesquisa foi aprovado pelo Comitê de Ética com número CAAE: 55413216.3.0000.5580.

\subsection{Mapeamento das redes sociais em comunidades de aprendizagem sobre nutrição infantil e BLW}

O mapeamento realizado para as 10 comunidades fez um levantamento quantitativo das postagens ao longo de um semestre, analisando três postagens de cada comunidade (totalizando 30 postagens). Foram levantados os seguintes dados para cada uma das comunidades: Rede social em que se insere; Nome da Comunidade; Tipo (perfil ou grupo); URL de acesso; Quantitativo de postagens nas categorias mídia (texto, imagem, vídeo) e autoria (própria, membro ou compartilhamento); Análise de 3 postagens para cada Comunidade, contemplando: título, data, hora, conteúdo, número de curtidas, comentários e compartilhamento.

As redes sociais escolhidas foram Facebook (FB) e Instagram por serem mais utilizadas no Brasil, tendo grande influência como formadoras de opinião em grupos e perfis que funcionam como comunidades de aprendizagem. O quadro a seguir apresenta os dados básicos das 10 comunidades participantes da pesquisa:

Quadro 1 - Comunidade de Aprendizagem analisadas na pesquisa

\begin{tabular}{|c|c|c|c|c|c|c|c|c|}
\hline Nome & $\mathrm{RS}^{*}$ & Tipo & $\mathrm{N}^{0}$ partic. & URL & Texto & Image & Vídeo & Total \\
\hline BLW Brasil-Baby led weaning & $\mathrm{F}$ & Grupo & 9075 & /www.facebook.com/groups/IABlw & 670 & 251 & 77 & 998 \\
\hline Baby led weaning BR & $\mathrm{F}$ & Grupo & 807 & www.facebook.com/groups/998385166885570/ & 12 & 9 & 4 & 25 \\
\hline Baby led weaning & $\mathrm{F}$ & Grupo & 51582 & www.facebook.com/groups/2855840155 & 5016 & 2297 & 385 & 7698 \\
\hline $\begin{array}{l}\text { Falando de intro dução } \\
\text { alimentar }\end{array}$ & $\mathrm{F}$ & Grupo & 7607 & $\begin{array}{l}\text { www.facebook.com/groups/faland } \\
\text { odeintroducaoalimentar/ }\end{array}$ & 205 & 41 & 7 & 253 \\
\hline Tá na hora do papá & $\mathrm{F}$ & Página & 69.707 & www.facebook.com/tanahoradopapa/?fref=ts & 94 & 251 & 72 & 417 \\
\hline Alimentação consciente & $\mathrm{F}$ & Grupo & 39071 & www.facebook.com/groups/alimen tacaoconsciente/ & 423 & 265 & 20 & 708 \\
\hline Mundo BLW & I & Perfil & 31.500 & www.instagram.com/mundoblw/ & 0 & 11 & 18 & 29 \\
\hline Nutri_infantil & I & Perfil & 115.000 & https://www.instagram.com/nutri_infantil & 66 & 72 & 5 & 143 \\
\hline Maternutri & I & Perfil & 46.100 & https://www.instagram.com/maternutri & 48 & 84 & 17 & 149 \\
\hline Tá na hora do papá & I & Perfil & 46.000 & https://www.instagram.com/tanahoradopapa & 9 & 239 & 42 & 290 \\
\hline
\end{tabular}

Fonte: Elaborado pelas autoras. Nota: ${ }^{*} \mathrm{RS}=$ Rede Social; F = Facebook; I = Instagram

As comunidades sintetizadas no Quadro 1 foram selecionadas por serem relevantes no cenário, uma vez que apresentam número expressivo de participantes e por serem produtoras de conteúdo de qualidade. Para a análise das postagens, foi considerado o tipo texto, imagem ou vídeo. Postagens do tipo texto foram consideradas publicações que continham narrativas, textos descritivos, argumentativos ou expositivos com finalidade de troca de informações, independente da linguagem utilizada, sendo ela coloquial ou formal. Postagens que continham imagens em que o conteúdo principal era o texto, sendo a imagem ilustrativa, foram consideradas textos. Essa compreensão é importante, especialmente para a rede social Instagram. Por ser uma rede social de compartilhamento de fotos, todos os compartilhamentos precisam conter imagens. Assim, para mapeamento dessa rede, todas as fotos seguidas de um texto mais significativo que a imagem, foram consideradas publicações do tipo texto. 
Publicações do tipo imagem foram classificadas como aquelas que não continham textos significativos atrelados à postagem, contendo, no máximo, legendas. Postagens do tipo vídeo foram caracterizadas por vídeos acompanhados ou não de textos de chamada em que o vídeo era mais relevante que o texto.

Analisando as comunidades selecionadas, nota-se que os perfis do Instagram possuem número maior de seguidores em relação aos grupos do Facebook, porém a quantidade de postagens é bem menor, o que condiz com o estilo de utilização dessas redes sociais. O Facebook, por formar grupos, apresenta maior interatividade com os usuários; ao contrário do Instagram, que apresenta uma rede social mais passiva baseada em perfis e seguidores e com a maior parte dos usuários observando e curtindo postagens. O quantitativo de postagens por mídia nas 10 comunidades ocorreu da seguinte forma: Texto 6.543 postagens (63\%); Imagem 3.250 postagens (31\%); Vídeo representou 6\% das postagens (647 ocorrências).

O Instagram destina-se a mídias do tipo fotos e vídeos, sendo que esses últimos têm até um minuto (mudança ocorrida em 2017, pois antes era, no máximo, 15 segundos). Disponibiliza opções de conversas diretas, o que ajuda a construir uma base de comunicação direta com o perfil que um usuário segue. Por outro lado, o Facebook acaba sendo uma rede de múltiplas opções, pode-se escolher e usar grupos, eventos, páginas em assuntos específicos, fotos, vídeos, textos etc., conforme a necessidade do conteúdo de cada post em si. Por outro lado, o Instagram é mais limpo, pois o usuário pode receber todo o conteúdo daqueles que segue a todo momento, estabelecendo uma audiência menor, porém com mais visibilidade.

O Instagram apresentou mais postagens de imagens do que textos, ao contrário das comunidades de aprendizagem do Facebook, que produzem maior quantidade de conhecimento por meio de textos narrativos, o que reafirma as características de cada rede. Em uma visão generalizada das duas redes sociais avaliadas, foram 10.710 postagens no período observado, sendo que os textos representaram $63 \%$ do total. Comparando o uso realizado nessas comunidades com o uso em perfis pessoais de estudantes de medicina (POSSOLLI; NASCIMENTO, 2016), percebe-se que a hierarquia do uso das mídias apresenta uma relação semelhante, o que se atribui às características de usabilidade das ferramentas dessas redes sociais. Na referida pesquisa, realizada em 2016 com 195 estudantes de medicina, a postagem de textos obteve prevalência de $53 \%$, imagens $26 \%$ e vídeo $21 \%$. Nessa pesquisa, foram incluídas outras redes sociais como WhatsApp, Snapchat e Linkedin, o que reduziu o número de postagem de imagem. Na presente pesquisa, que focou Facebook e Instagram, o número de imagens foi mais representativo, uma vez que o Instagram é uma rede social pensada para o compartilhamento de fotos de seus usuários.

Observa-se um predomínio de postagens de autoria própria nessas comunidades, superando o contingente que postagens compartilhadas de outras fontes. Isso demonstra que, nessas comunidades de aprendizagem, o conhecimento é produzido, normalmente, pelos usuários e moderadores dos grupos que geram conteúdo on-line ou selecionam artigos e materiais, atuando de uma forma mais ativa. Vários desses conteúdos são vídeos explicativos ou fotos demonstrativas relacionadas ao BLW. Com referência à pesquisa de Possolli e Nascimento (2016), os dados obtidos são divergentes daqueles coletados de acordo com os quais se tem que $86 \%$ dos usuários se dizem passivos frente à rede social, isto é, compartilham e curtem conteúdo muito mais do que realizam postagens de autoria própria (14\%). O que corrobora com a ideia de que esses usuários, enquanto interessados e estudantes da área de saúde, publicam, por meio de compartilhamentos, os conteúdos que comunidades de aprendizagem produzem. Nessa pesquisa, como o foco não foi os usuários e sim, as comunidades, nota-se uma atenção à produção de conteúdos a serem compartilhados pelos usuários membros do grupo. 


\subsection{Análise das postagens em comunidades de aprendizagem}

O gráfico1 apresenta quantitativo de postagens por mídia nas 10 comunidades, auxiliando na compreensão da relevância de conhecimento produzido nessas comunidades.

\section{Gráfico 1-Quantitativo de postagens por midia}

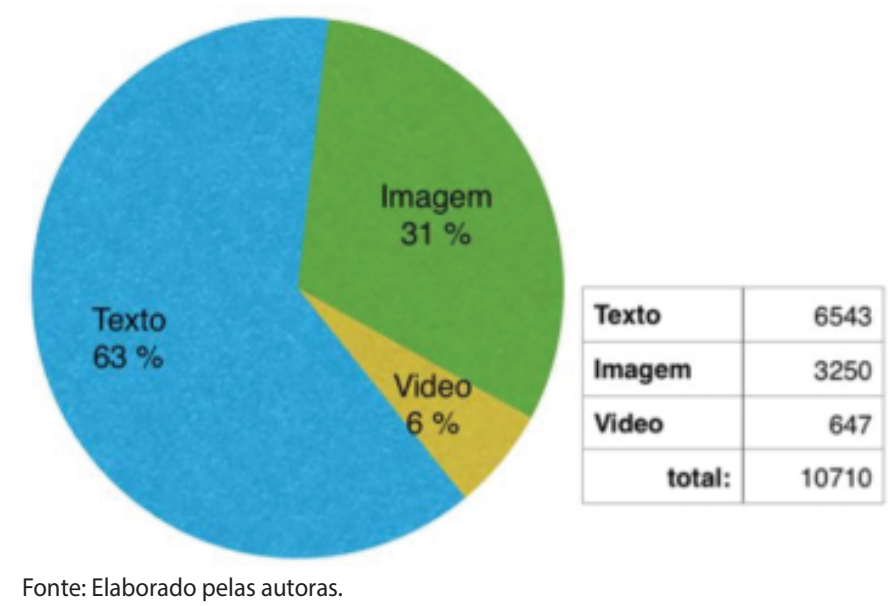

O Instagram apresentou mais postagens de imagens do que textos, ao contrário das comunidades de aprendizagem do Facebook, que produzem maior quantidade de conhecimento por meio de textos narrativos, o que reafirma as características de cada rede. Em uma visão generalizada das duas redes sociais avaliadas, foram 10.710 postagens neste período, sendo que os textos representaram $63 \%$ do total. Comparando o uso realizado nessas comunidades com o uso em perfis pessoais de estudantes de medicina (POSSOLLI; NASCIMENTO, 2016) percebe-se que a hierarquia do uso das mídias apresenta uma relação semelhante, o que se atribui as características de usabilidade das ferramentas dessas redes sociais. Na referida pesquisa, realizada em 2016 com 195 estudantes de medicina a postagem de textos obteve prevalência de $53 \%$, imagens $26 \%$ e vídeo $21 \%$. Nessa pesquisa foram incluídas outras redes sociais como WhatsApp, Snapchat e Linkedin, o que reduziu o número de postagem de imagem. Na presente pesquisa, que focou Facebook e Instagram, o número de imagens foi mais representativo uma vez que o Instagram é uma rede social pensada para o compartilhamento de fotos de seus usuários

\section{Gráfico 2- Quantitativo de postagensporautoria}

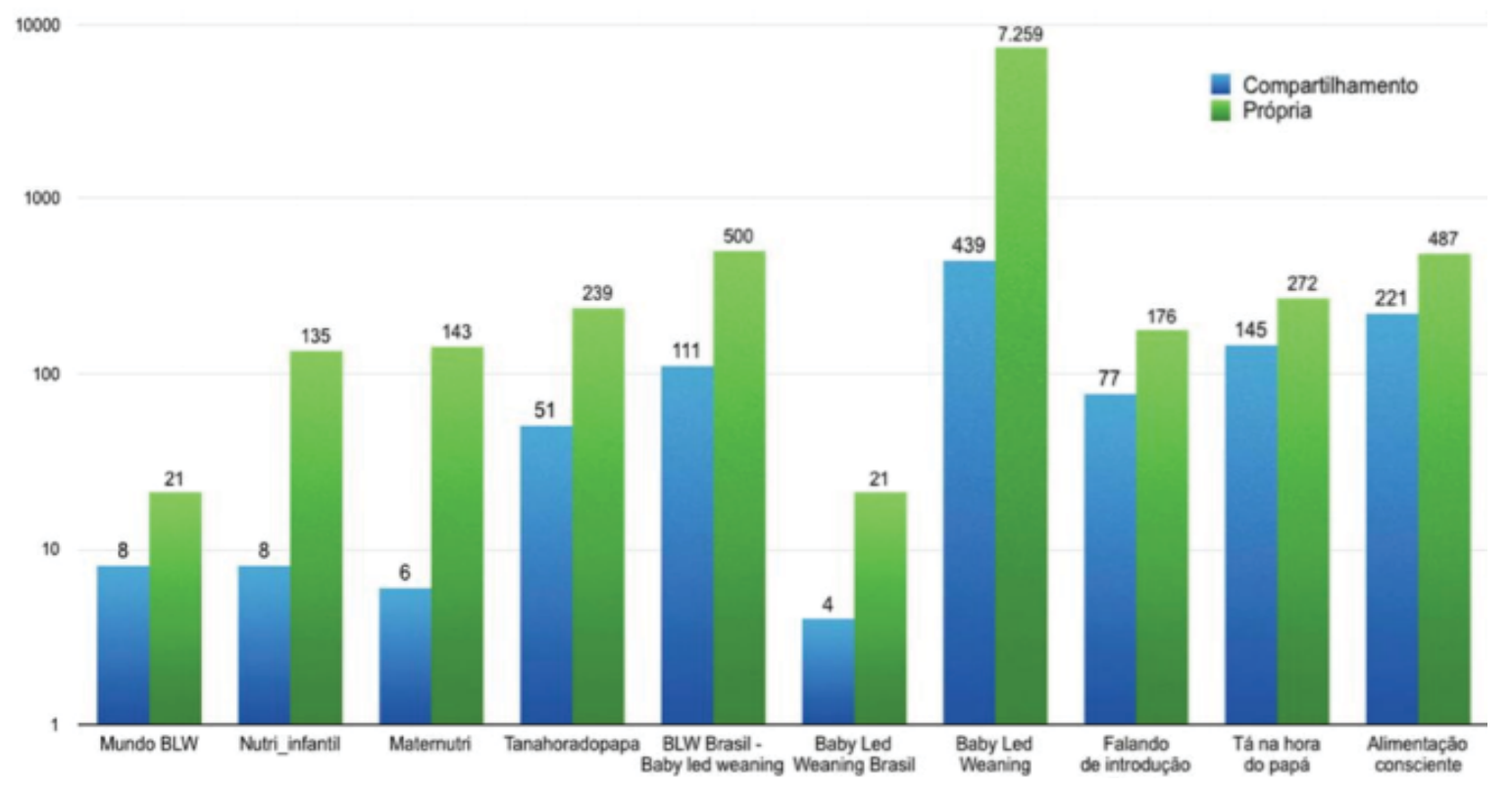


Observou-se um predomínio de postagens de autoria própria. Isso demonstra que, nessas comunidades de aprendizagem, o conhecimento é produzido, normalmente, pelos usuários e moderadores dos grupos que geram conteúdo on-line ou selecionam artigos e materiais, atuando de forma ativa. Muitos desses conteúdos são vídeos explicativos ou fotos demonstrativas sobre o BLW.

\subsubsection{BLW Brasil}

A comunidade de aprendizagem BLW Brasil é um grupo fechado do Facebook, com 9.075 participantes e 4 administradores. Como objetivos desse grupo de aprendizagem, destacam-se o apoio ao aleitamento materno exclusivo em livre demanda até os 6 meses, o aleitamento prolongado até 2 anos ou mais, estímulo de uma introdução alimentar saudável e participativa. Seguem protocolos da Organização Mundial de Saúde, da Sociedade Brasileira de Pediatria e do Ministério da Saúde. O grupo proíbe propagandas de produtos, fórmulas lácteas ou remédios, assim como desestimulam o uso de bicos artificiais e mamadeiras.

Postagens são moderadas pelos administradores que filtram o conteúdo, seguindo os protocolos acima citados, sendo que as postagens são em maioria dos próprios membros. No período analisado, foram 998 postagens, a maioria em forma de textos. Observou-se que as postagens geram debates com muitos comentários, trocas de informações e relatos. As administradoras respondem dúvidas geradas embasadas em dados científicos.

Quadro 2 - Postagens selecionadas no grupo BLW Brasil

\begin{tabular}{|c|c|c|}
\hline Data & Assunto & Conteúdo \\
\hline $26 / 07$ & Regras do & $\begin{array}{l}\text { S.B (Moderadora do grupo) Como eu sempre repito. Vamos falar de BLW? } \\
\text { Antes de mais nada, leia, procure um profissional atualizado para te dar orientação! É importante confiar no bebê e em si } \\
\text { mesmo! Vamos às regras: 1. Não postar incentivo a tipos de introdução alimentar ou alimentação infantil que não sejam guiadas } \\
\text { pela criança; 2. Estar ciente que esse grupo é para apoio que de forma alguma dispensa orientação e acompanhamento de } \\
\text { um bom pediatra; } 3 \text {. Postagens não relacionadas ao tema da comunidade não serão autorizadas. }\end{array}$ \\
\hline $09 / 062016$ & Engasgo & $\begin{array}{l}\text { Postagem inicial de D.V.M: Mamães, esse mês começo a introdução alimentar do meu bebê, e desejo BLW... Porém essa semana } \\
\text { surgiu uma insegurança, pois uma mamãe praticante da IA BLW me disse da importância de saber realizar a MANOBRA DE } \\
\text { HEIMLICH em caso de engasgo. Qual a opinião das que realizam BLW?? Respostas: } \\
\text { S.B: Eu acredito que todos os cuidadores devem saber, independente da forma da IA, a criança pode engasgar com qualquer } \\
\text { coisa, e temos que estar preparados. } \\
\text { M.D: Olá! Saber a Manobra de Heimlich é importante não só para engasgo com alimentos, pois também podem ser com } \\
\text { líquidos e objetos. http://womanslounge.com.br/como-desengasgar-o-bebe }\end{array}$ \\
\hline $\begin{array}{l}28 / 09 \\
2016\end{array}$ & $\begin{array}{c}\text { Criança sem } \\
\text { apetite }\end{array}$ & $\begin{array}{l}\text { Postagem inicial de A.M.: Olá Minha filha está com } 9 \text { meses e } 12 \text { dias. LM em LD. Nasceu prematura, tomou fórmula, usou chupeta, } \\
\text { mamadeira, mas fui tirando tudo, convicta que a amamentação era o melhor para ela. Muito Tetê. Chegamos aos } 6 \text { meses e comecei } \\
\text { a IA. Não fluiu... Esperei mais um pouco para a idade corrigida chegar. Nada! São praticamente } 3 \text { meses tentando. Ela simplesmente } \\
\text { não come. Às vezes demonstra interesse em pegar, amassar, espremer, mas comer não. Poucas vezes, pouquíssimas mesmo ela } \\
\text { levou a boca. Já sai do BLW, ofereci a IA "tradicional" e nada. Pelo contrário, ela nem colher aceita, nenhum tipo de suco, chá, nada! } \\
\text { Tomar um remédio é um parto de quadrigêmeos. Alguém com história parecida? Alguma luz? Acham que devo procurar algum } \\
\text { especialista? Pode ser algo fisiológico? } \\
\text { Respostas: S.L: Olá Ana } \\
\text { adianta seu bebê só vai comer quando e o quanto quiser o dia que quiser... Passei um tempo me sentindo frustrada buscando } \\
\text { explicação .... E não, não existe .... Tem dias que como ontem passou o dia com uma rodela de banana,... Quando vou na pediatra } \\
\text { ela diz: sua bebê está saudável! Não tem anemia, tudo ok relaxa... Nas minhas buscas li algo super bacana que dizia que eles } \\
\text { possuem reservas e que essa falta de interesse pode ir até os } 24 \text { meses e o pouco que comer seja um grão de arroz é o que } \\
\text { estava precisando no momento. Sabe eu faço o meu papel todos os dias... Faço todas as refeições pratos coloridos, variados e } \\
\text { coloco à disposição dela e ela decide!!! Nunca cedi a (não está comendo oferecer algum substituto não saudável) .... Aprendi } \\
\text { que sim ela não é um padrão ela é única e deixo rolar no tempo dela sem crise, sem drama, e ficou tudo tão mais leve para nós } \\
\text { duas... Gosto de cozinhar para ela e sim ficaria muito feliz se ela devorasse, mas ela é a autora dessa história toda... Confie } \\
\text { de tempo... Não desista, mesmo que o bebê não toque em nada.... Se ele está bem, saudável se desenvolvendo, tranquiliza } \\
\text { seu coração de mãe. } \\
\text { K.C: Um texto que me ajudou muito foi: http://grupovirtualdeamamentacao.blogspot. com.br/...tras... (Transcrição e tradução } \\
\text { do vídeo do Dr. González) }\end{array}$ \\
\hline
\end{tabular}

Fonte: Elaborado pelas autoras.

Fangupo et al. (2016) afirma que não houve aumento de engasgos quando utilizado - BLW, porém afirma que ainda são poucos os estudos a respeito da abordagem. Independente do tipo de introdução complementar utilizada, o risco de engasgo em lactentes é existente e saber realizar a manobra de Heimlich é importante. Ferreira e 
Garcia (2001, p. 222) descrevem a manobra como: "A manobra de Heimlich por meio de pressão abdominal eleva o diafragma, aumentando a pressão do ar, forçando-o para fora dos pulmões, que pode ser suficiente para criar tosse artificial, e expelir o corpo estranho das vias aéreas." Em relação à postagem da criança que não apresenta apetite, segundo sua mãe, é uma das queixas mais frequentes no cotidiano do médico pediatra. Fisberg, Tosatti e Abreu (2014, p. 3) afirmam:

\begin{abstract}
Quase sempre, uma queixa de que a criança não come, exprime um grito de angústia para todos os pais, por atentar especialmente para a incapacidade de alimentar seus filhos, num inconsciente coletivo silencioso de não atendimento a sobrevivência das espécies. Esta situação, na maior parte das vezes, determina um quadro de pouco apetite, apetite muito seletivo ou uma enorme incapacidade de entender as necessidades nutricionais das crianças pequenas. O próprio profissional de saúde pode ser pressionado pela família a interceder de alguma forma, caindo no círculo vicioso da pressão para que a criança coma mais, sem entender a dificuldade.
\end{abstract}

Esse autor ainda afirma que menos de $10 \%$ dos casos de recusa alimentar se devem a causas orgânicas e é necessário evitar que a ânsia por dar comida para a criança já alimentada gere práticas inadequadas. As moderadoras da comunidade de aprendizagem avaliada publicaram diversos artigos, vídeos e textos explicativos, reafirmando a importância do conhecimento e da prática da manobra do desengasgo. Conclui-se, após avaliação dos conteúdos das postagens, que essa comunidade virtual de aprendizagem produz e compartilha conteúdo com evidências científicas de forma atualizada e sempre buscando literatura adequada para justificar ideias e debater controvérsias.

\title{
3.2.2 Baby led weaning Brasil
}

Comunidade do Facebook, constituída de 807 membros (até o momento da coleta) e 3 administradores que não especificam se são profissionais da área da saúde, com o objetivo definido mais específico de educar sobre o método BLW, manter o foco e as discussões voltadas para o mesmo, e, assim, discutir tudo o que for relacionado ao BLW. A comunidade orienta que as informações não substituem as orientações dos profissionais de saúde, porém fazem o possível para gerar conhecimento com o intuito claro de que os usuários possam discutir suas decisões e as decisões dos profissionais da saúde com base científica com o objetivo de qualidade alimentar na nutrição seus filhos. As postagens não necessitam de aprovação dos administradores, porém se apresentam conteúdo inadequado são excluídas. A comunidade não apresenta grande número de postagens, que são exclusivamente relacionadas ao método BLW, no período analisado, houve um total de 25 postagens, sendo o predomínio novamente do tipo texto.

A maioria das postagens (670) foram em formato textual, com ou sem imagem ilustrativa, reafirmando a prevalência desse tipo de mídia no Facebook. Postagens em que fotos ou imagens que obtiveram maior número de curtidas representaram 251 no período rastreado e 77 em formato de vídeo. A seguir, o quadro apresenta três postagens selecionadas do grupo Baby led weaning Brasil em que os assuntos foram: Regras do Grupo, Introdução Alimentar e Como usar arroz e feijão no BLW:

Quadro 3 - Postagens selecionadas no grupo Baby Led Weaning Brasil

\begin{tabular}{|c|c|l|}
\hline Data & Assunto & \multicolumn{1}{c|}{ Conteúdo } \\
\hline $26 / 07$ & $\begin{array}{c}\text { Regras do } \\
\text { Grupo }\end{array}$ & $\begin{array}{l}\text { O grupo Baby Led Weaning Brasil foi criado com o intuito de nos educarmos sobre o método; nos auxiliarmos a manter o } \\
\text { foco no mesmo; e discutir tudo que for lacionado ao BLW. Para mantermos a organização e foco do grupo, é importante } \\
\text { seguirmos algumas regras: } \\
\text { - Seja cortês. Não julguemos ninguém, para criarmos comunidade para esclarecer dúvidas e nos guiar no método BLW. }\end{array}$ \\
\hline & $\begin{array}{l}\text { - O foco do grupo é o método Baby Led Weaning e pedimos que todos os membros colaborem para mantermos este foco. } \\
\text { Nós entendemos que nem todos praticam o método e temos a intenção de acolher a alimentação passiva serão redirecionadas } \\
\text { para que ocorra fora do grupo. }\end{array}$ \\
\hline
\end{tabular}




\begin{tabular}{|c|c|c|}
\hline $\begin{array}{l}18 / 10 \\
2016\end{array}$ & $\begin{array}{c}\text { Introdução } \\
\text { Alimentar }\end{array}$ & 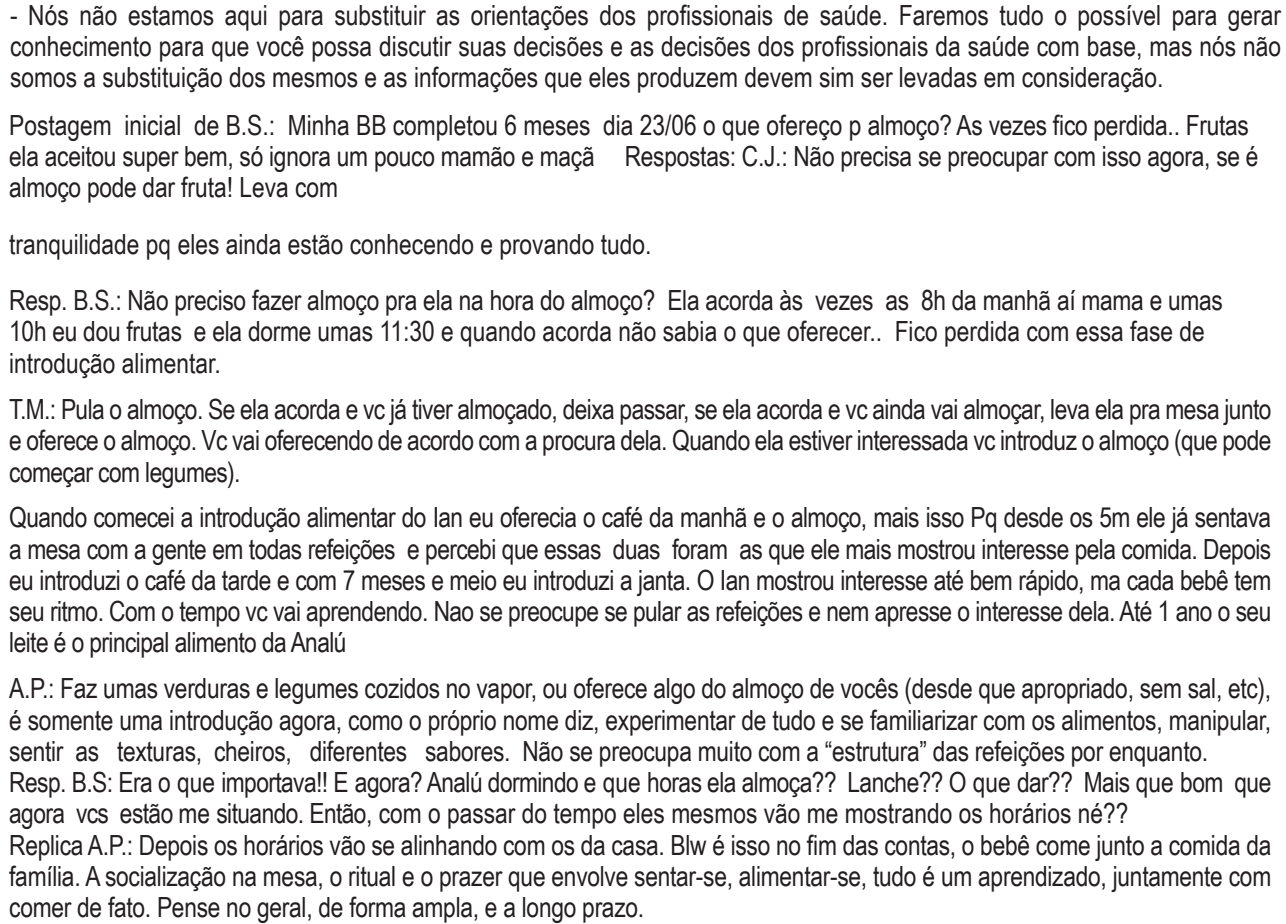 \\
\hline $\begin{array}{l}28 / 05 \\
2016\end{array}$ & Arroz e Feijão & $\begin{array}{l}\text { Postagem inicial de M.C.M.: Gente desculpa a ignorancia mas como usar o BLW pra oferecer o arroz e feijao? Respostas: } \\
\text { C.J.: Melhor oferecer quando ja tem o movimento de pinça dos dedos, bem desenvolvido. Antes disso melhor em bolinhos. } \\
\text { É o que faço. E esmago o arroz pra fazer. } \\
\text { R.A.: Faz bolinho de feijão. Só deixar o feijão al dente, quando esmagar ele fica mais firme, acrescenta farinha de aveia } \\
\text { para dá o ponto. Resp. R.A.: Bolinho de arroz, feijão e farinha de aveia. }\end{array}$ \\
\hline
\end{tabular}

Fonte: Elaborado pelas autoras.

$\mathrm{Na}$ primeira postagem selecionada, uma das administradoras do grupo, inseriu orientações para uso adequado do grupo por todos os participantes, buscando manter o foco, a cordialidade e uma interação produtiva. Essas orientações são importantes e deixam claro as motivações do grupo em seguir os princípios do Baby Led Weaning, deixando explícito que a comunidade tem um intuito educativo e de aprendizagem coletiva ao dizer que "o intuito de nos educarmos sobre o método BLW." Estabelecendo como regra a cordialidade para esclarecer dúvidas, manter o foco no BLW, proibição de falar sobre alimentação passiva.

Destaca-se o fato de que os administradores dos grupos deixam claro que as discussões e orientações no grupo não substituem "as orientações dos profissionais de saúde". Essa consideração está em consonância com uma grande preocupação dos profissionais da saúde sobre a qualidade das informações veiculadas na web e o fato de os pacientes buscarem orientações na Internet, que são levadas ao consultório ou ainda que são seguidas sem o consentimento desses profissionais. Nesse sentido, UNIMED (2014) sintetiza essa preocupação e como encaminhar essas situações:

A revolução comportamental causada pela internet e o acesso ao conhecimento modificou a tradicional relação médico-paciente. Não adianta jogar os sintomas na rede, sem saber avaliá-los. Uma vez que um único sintoma pode ser comum a milhares de doenças, somente uma avaliação criteriosa, feita em consultório, e acompanhada de exames pode comprovar um diagnóstico e indicar um tratamento. As informações que estão na internet devem ser utilizadas a título de orientação. Dar informações genéricas sobre saúde e bem-estar está dentro da legalidade, mas, prestar assistência médica à distância através de qualquer meio que não seja o presencial, é considerado antiético pelo Conselho Federal de Medicina (CFM). Você até pode orientar-se com fontes seguras do 'Doutor Google' e em seguida agendar uma consulta médica. 


\subsubsection{Baby Led Weaning}

A comunidade internacional do Facebook, com 51.582 participantes de diversos países, difere das comunidades citadas por ser um grupo aberto com 5 administradores. Tem como objetivos aguardar até 6 meses para introduzir qualquer tipo de comida (exceto leite materno ou artificial), orienta que os pais deixem a criança explorar e experimentar toda a dieta da família, desestimula a consistência de papas amassadas e uso de colheres. Orienta que participantes praticantes do método tradicional que não queiram iniciar o BLW procurem grupos de aprendizagem sobre introdução alimentar tradicional, pois as pessoas desse grupo não utilizam colheres ou consistências pastosas de alimentos. Postagens anti-BLW ou de conteúdo inadequado são excluídas. Nessa comunidade, as postagens são mais focadas para o método da oferta do alimento do que da qualidade nutricional, além de uma variedade de alimentos ofertados diferentes das comunidades nacionais, justamente por ser um grupo que possui participantes de países distintos. No quadro 4 , transcrevem-se três postagens significativas do grupo:

Quadro 4 - Postagens selecionadas no grupo Baby Led Weaning

\begin{tabular}{|c|c|c|}
\hline Data & Assunto & Conteúdo \\
\hline $\begin{array}{l}20 / 10 \\
2016\end{array}$ & $\begin{array}{l}\text { Alimentos } \\
\text { oferecidos }\end{array}$ & $\begin{array}{l}\text { First food for } 6 \text { month old? She'll be } 6 \text { months old on November 3rd and we've been exclusively breastfeeding this whole } \\
\text { time. Respostas: } \\
\text { C.S: Abacate, batata doce, brócolis no vapor, cenoura cozida são ótimos! Cortá-los para cerca do tamanho do ponteiro e } \\
\text { dedo médio e deixar o bebê agarrá-los e se auto “alimentar". No início, eles não vão realmente comer muito, mas eles estão } \\
\text { recebendo a experiência de alimentos e suas texturas. É uma abordagem de desmame guiado pelo bebê. Para fazer } \\
\text { BLW a criança tem que mostrar sinais de prontidão de desenvolvimento para começar sólidos, incluindo ter pelo menos } 6 \\
\text { meses, sentar sozinho, ter primeiro dente, e demonstrar interesse em alimentos, mastigação. A principal fonte primária de } \\
\text { nutrição é leite materno ou fórmula. Você pode encontrar informações online ou há um livro na maioria das bibliotecas públicas } \\
\text { explicando. }\end{array}$ \\
\hline $\begin{array}{l}24 / 09 \\
2016\end{array}$ & $\begin{array}{l}\text { Literatura a } \\
\text { respeito }\end{array}$ & $\begin{array}{l}\text { Olá a todos! Eu sou nova para o grupo e terei uma menina no início de novembro. Eu ouvi grandes coisas sobre BLW e } \\
\text { queria saber se alguém poderia compartilhar alguns bons artigos, livros, ou mesmo apenas dicas para alguém como eu } \\
\text { que não sabemuito sobre o BLW (Além disso, também quero tentar convencer o marido a fazer isso porque ele é duvidoso } \\
\text { quanto a abordagem). Eu sei que amigos meus o fizeram e falaram muito bem, então estou muito intrigada para aprender. } \\
\text { Obrigada! Respostas: Comecei a ler este livro. Eu sou novo também. Meu bebê tem } 4 \text { meses. Eu quero fazer BLW. } \\
\text { Indicação do livro: Baby-led Weaning: Helping Your Baby To Love Good Food - Gill Rapley, Tracey Murkett }\end{array}$ \\
\hline $\begin{array}{l}27 / 06 \\
2016\end{array}$ & Creche & $\begin{array}{l}\text { Alguém faz BLW e leva seu bebê para creche? Com o meu primeiro eu fiz desmame tradicional, mas gostaria de tentar BLW } \\
\text { com o segundo, ele terá de } 6 \text { meses. Quero saber se o BLW daria certo na creche. Respostas: K.W: Minha filha frequenta } \\
\text { creche Montessori e ajudam a jornada BLW. Acho muito bom para a equipe também. Eles alimentam todos os bebês então } \\
\text { minha filha senta e fica comendo sozinha. Eles comentaram que desejariam que todos os bebês praticassem BLW também. }\end{array}$ \\
\hline
\end{tabular}

Fonte: Elaborado pelas autoras.

Nota-se, nas postagens e nas respostas, informações concordantes com o preconizado, como cita a usuária que respondeu a pergunta e que orientou quanto aos sinais de prontidão e aptidão do bebê para o início da introdução alimentar. A Sociedade Brasileira de Pediatria divulgou uma atualização em maio de 2017 sobre a alimentação complementar e o método BLW em que cita: "Entender os sinais de maturidade do lactente para introdução de alimentos sólidos é fundamental para uma alimentação complementar com sucesso" (WEFFORT et al., 2017, p. 1).

$\mathrm{Na}$ segunda postagem, observa-se preocupação em buscar conhecimento científico e informação sobre BLW, até mesmo para levar essa informação aos demais parentes. Isso confirma que o fluxo da comunicação científica tem se favorecido das comunidades virtuais e fóruns de discussões. Castro (2006) afirma que o movimento de acesso aberto dos últimos anos, garante a publicação livre de documentos em meio eletrônico, desde que com a devida citação e preservação de direitos autorais, facilitando o desenvolvimento de pesquisas e a preparação de trabalhos em redes. O livro citado pela usuária que respondeu a postagem é o livro referência da abordagem BLW escrito pela pioneira Gill Rapley (2008).

\subsubsection{Falando de introdução alimentar}

Essa comunidade conta com 17.607 participantes no Facebook com o interesse em comum acerca de alimentação rica, saudável e balanceada, promove o aleitamento materno e comida com qualidade de nutrientes. Dentre as comunidades analisadas, é a 
que mais possui informação científica sobre o assunto, com um arquivo de dúvidas para auxiliar os participantes. A maior comunidade dentre as analisadas (Baby Led Weaning) dispõe de 15 arquivos on-line, a comunidade "Falando de introdução alimentar" apresenta 65 arquivos disponíveis para download, que incluem manuais de nutrologia, manual da Sociedade Brasileira de Pediatria sobre alimentação, roteiros de como iniciar a introdução alimentar, compilações de artigos científicos sobre diversos assuntos. De forma didática, disponibilizam também vídeos e artigos do pediatra Dr. Carlos Gonzalez, que é referência na pediatria humanizada, aleitamento materno e nutrição infantil. Apresenta também um artigo de como pesquisar na ferramenta de busca Google. As postagens não são exclusivas sobre o método BLW e os assuntos mais postados são sobre quais alimentos oferecer, qual a quantidade ideal ofertada e dúvidas habituais que são respondidas pelos próprios participantes e pelas administradoras do grupo que, frequentemente, orientam a literatura científica.

Quadro 5 - Postagens selecionadas no grupo Falando de introdução alimentar

\begin{tabular}{|c|c|c|}
\hline Data & Assunto & Conteúdo \\
\hline $28 / 11$ & do apetite & $\begin{array}{l}\text { Oi pessoal, estou sempre lendo e aprendendo muito com as informações trocadas aqui é como meu } \\
\text { bebê comia muito e muito bem, não imaginava que fosse ter que pedir ajuda pra vocês tão cedo. Acontece que meu filho acabou } \\
\text { de fazer um ano e desde uns dias antes do aniversário dele ele começou a comer cada vez menos, eu pensei que fosse por } \\
\text { causa dos dentinhos que estão nascendo, mas ele nunca tinha perdido o apetite assim e nem ficado sem dormir durante a } \\
\text { noite o que também começou a acontecer nesses dias. Eu pesquisei em alguns sites e vi que seria normal nessa fase ele diminuir } \\
\text { a quantidade de comida, só que de } 1 / 4 \text { do que ele comia antes e das frutas e leite, agora ele mal come uma colherada e até as } \\
\text { frutas ele está começando a recusar. Estou tentando não surtar mas está difícil. O peso dele é bom tem 10,600, mas pra melhorar } \\
\text { hoje depois de uma noite em claro ele está bem gripado, como nunca esteve antes. Apesar de tudo continua super ativo como } \\
\text { sempre. Alguém passou por isso? Quando devo ir ao médico, posso continuar a oferecer as coisas que ele gosta depois te tentar } \\
\text { oferecer a comida??? (ele só come comida caseira, nada industrializado,frutas, pão e leite materno em livre demanda). Obrigada! } \\
\text { Respostas: J.L: Oi! Se te tranquiliza, a maioria passa por essa fase. www.maternidadecol orida.com.br/1-ano-e-a-crianca/ }{ }^{*} \text { link } \\
\text { de artigo relacionado ao assunto do pediatra Carlos González }\end{array}$ \\
\hline $\begin{array}{l}25 / 11 \\
2016\end{array}$ & $\begin{array}{c}\text { Sucos e } \\
\text { postagem } \\
\text { informativa }\end{array}$ & 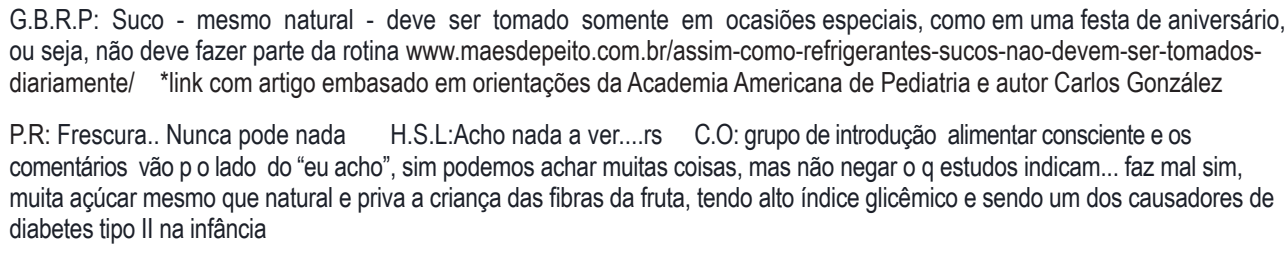 \\
\hline $29 / 01$ & Pediatra & S.L: Boa tarde!! Alguma mamãe de SP que conheça um bom pediatra no convênio \\
\hline 2017 & & $\begin{array}{l}\text { Santa Helena? A pediatra do meu bebê quer eu desmame ele com } 11 \text { meses... } \\
\text { Respostas: D.L: Ela que amamenta? (Cada coisa né !) isso quem deve decidir é você e não ela, lógico que é motivo pra trocar de } \\
\text { pediatra mesmo, pois ela seria uma pessoa em que você pudesse confiar, te passar informações corretas rs, percebe- de q isso ela não } \\
\text { faz, eu também troquei de pediatra quando meu bebe estava pra completar } 1 \text { ano, aos } 8 \text { meses ela me deu um papel de propaganda } \\
\text { do Danoninho e seus "benefícios" pra mim aquilo foi o fim rs, meu bebê hoje passa com uma ótima pediatra mas não sei se atende o } \\
\text { seu plano. } \\
\text { F.W.A.: Lógico que é motivo pra trocar de pediatra, pois precisa ser um profissional que você pussa confiar, te passar informações } \\
\text { corretas. Percebe-se q isso ela não faz. Eu também troquei de pediatra quando meu bebe estava pra completar } 1 \text { ano, aos } 8 \text { meses } \\
\text { ela me deu um papel de propaganda do Danoninho e seus "benefícios", pra mim aquilo foi o fim rs, meu bebê hoje tem uma ótima } \\
\text { pediatra. }\end{array}$ \\
\hline
\end{tabular}

Fonte: Elaborado pelas autoras.

A Academia Americana de Pediatria e a Sociedade Brasileira de Pediatria recomendam, há mais de três anos, o consumo de suco apenas a partir do primeiro ano de vida e de forma moderada. Conforme citado por Weffort et al. (2012, p. 28),

Os sucos naturais devem ser evitados, mas se forem administrados que sejam dados no copo, de preferência após as refeições principais, e não em substituição a estas, em dose máxima de $100 \mathrm{~mL} /$ dia, com a finalidade de melhorar a absorção do ferro não heme presente nos alimentos como feijão e folhas verde-escuras.

As frutas ofertadas na forma de suco perdem grande parte de suas fibras, além de hipersolicitar o pâncreas da criança (aumentando a chance de desenvolver diabetes tipo 2 ), ter uma quantidade muito grande de frutose e aumentar o consumo de calorias vazias da dieta. Infelizmente, a oferta do suco para bebês é prática recorrente em nosso meio, difundido, principalmente, pelos avós e, mesmo em um grupo de introdução alimentar, percebe-se que ainda alguns familiares julgam essa informação como exagero. Torna- 
se de grande importância esse tipo de postagem educativa em comunidades de aprendizagem, pois difundem conteúdo mais atualizado e debatem informações de forma científica, citando links, manuais e artigos recentes de Sociedades de Pediatria e Nutrição.

\subsubsection{Tá na hora do papá}

Página do Facebook com 69.707 seguidores, que tem como objetivo promover e disseminar conhecimento sobre alimentação infantil e também divulga o método BLW. A administradora da página promove debates e gera discussões (questiona como usuárias praticam o BLW se o bebê frequenta creche ou fica com avós/cuidadores), promove comparações das orientações da OMS e da prática dos usuários (exemplo: quando iniciaram a oferta de carnes X orientação da OMS), costuma colocar fonte das postagens, divulga vídeos e textos de profissionais de saúde, dispõe de aulas online e cursos sobre IA Participativa e BLW além de E-books gratuitos sobre o BLW. Diverge das comunidades por apresentar mais vídeos explicativos e demonstrativos e, ao contrário das demais comunidades analisadas, postou mais imagens do que textos (251 imagens, 72 vídeos e 94 textos).

Quadro 6 - Postagens selecionadas na página "Tá na hora do papá"

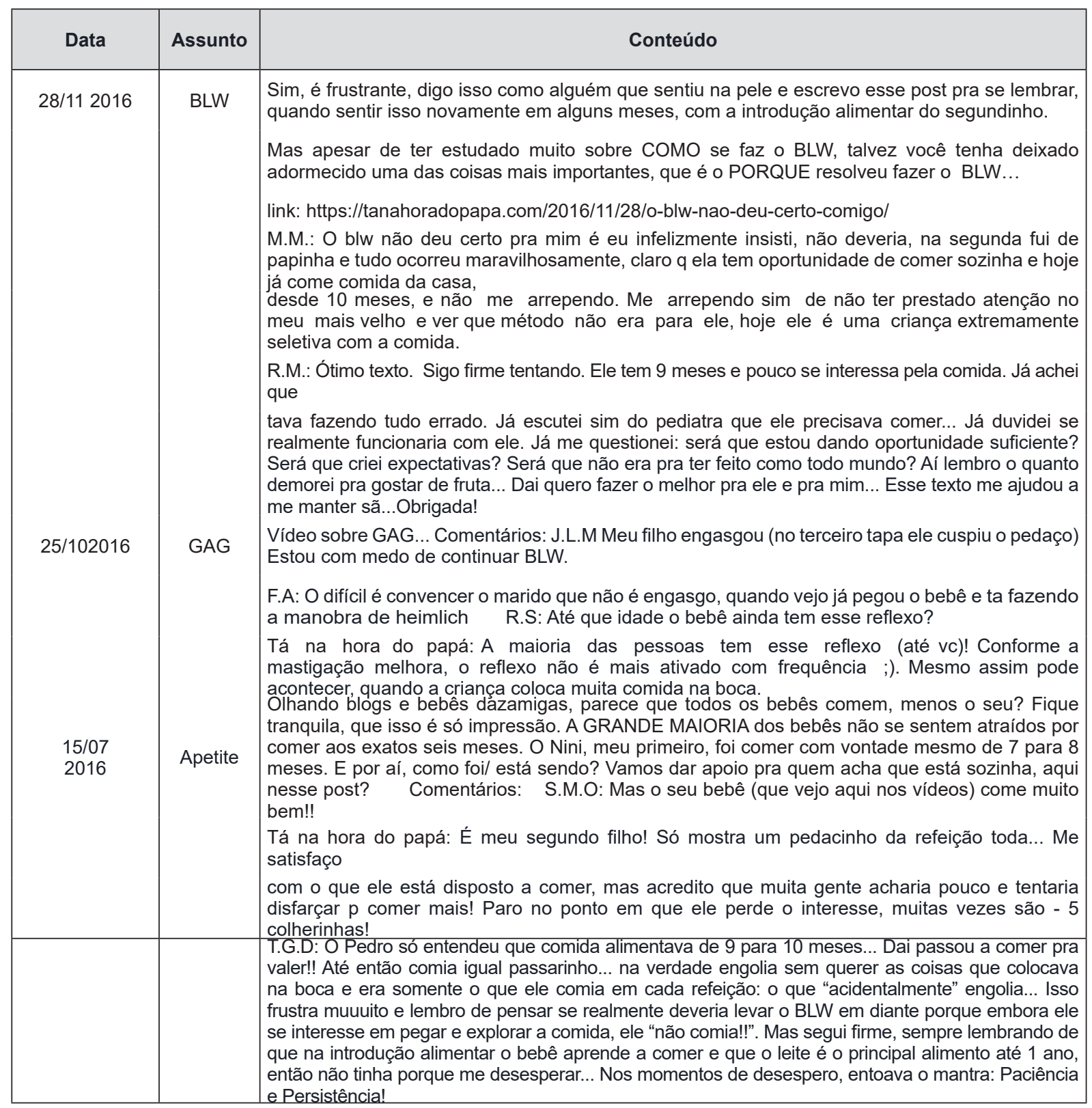

Fonte: Elaborado pelas autoras. 
O gag é constantemente citado quando falamos em BLW, apesar de ser um mecanismo de defesa fisiológico das vias aéreas do bebê, quando essa defesa ocorre costuma assustar os familiares, principalmente se esses nunca viram ou leram a respeito desse reflexo. Tal reflexo é muito similar a uma náusea/ânsia de vômito para que qualquer objeto estranho ou muito grande não seja deglutido e sim, trazido de volta para a frente da boca da criança. A criadora da página "Tá na hora do papá", frequentemente, posta vídeos explicativos sobre esse assunto. Isso é de extrema relevância para os familiares se informarem e saberem como agir durante o referido reflexo. Padovani (2015, p. 20) afirma:

\begin{abstract}
Essa primeira fase é fundamental na aprendizagem da mastigação e o bebê tem seus reflexos protetores em nível máximo de funcionamento - laringe e traquéia elevadas, dorso de língua elevado, reflexo de gag anteriorizado. Até que o corpo se acostume, e até que o bebê aprenda a manejar os alimentos em cavidade oral e toda sua anatomofisiologia comece a se modificar para ir ficando mais próxima do que temos quando adultos. Seria a melhor hora para investir em alimentos macios, fáceis do bebê manipular por conta própria. Tirinhas de cenoura, batata e outros legumes bem cozidos, raminhos macios de brócolis e couve flor, tiras de frutas macias como banana, mamão, abacate. Frutas macias como caqui, abacate, pêssego, ameixa, pêra. Confie no seu bebê. Suas habilidades motoras globais estão em perfeita sintonia com suas habilidades motoras orais.
\end{abstract}

É interessante destacar as postagens estimulando e apoiando os familiares a não se sentirem diferentes ou desanimados. Exemplo disso é a postagem do quadro em que a autora busca esclarecer que nem todos os bebês comem como seus pais gostariam. Isso não é anormal, vai de acordo com estudos que demonstraram que muitos usuários buscam as comunidades virtuais de aprendizagem para encontrarem apoio que podem não ter recebido do pediatra, familiares e amigos (D'ANDREA et al., 2016).

\title{
3.2.6 Alimentação consciente
}

Com número expressivo de participantes, 39.071, essa comunidade de aprendizagem do Facebook tem o foco na alimentação saudável para todas as crianças, principalmente na primeira infância. Apesar das postagens serem moderadas, notase que os perfis dos administradores são mais passivos e as postagens são em sua grande maioria publicadas pelos próprios participantes. O assunto principal são dúvidas, compartilhamento de receitas saudáveis, com alimentos orgânicos e sem ingredientes industrializados. Conta com arquivos de apoio, mas que são, em sua maioria, não científicos/acadêmicos.

Quadro 7 - Postagens selecionadas na comunidade "Alimentação consciente"

\begin{tabular}{|c|c|c|}
\hline Data & Assunto & Conteúdo \\
\hline $\begin{array}{l}29 / 11 \\
2016\end{array}$ & $\begin{array}{l}\text { Divulgação de } \\
\text { informação }\end{array}$ & $\begin{array}{l}\text { M.S.S: O Ministério da Saúde disponibiliza gratuitamente dois documentos norteadores da boa alimentação para os } \\
\text { brasileiros: o Guia Alimentar e o Guia Alimentos Regionais Brasileiros. Obs: A venda é proibida. Os links para download dos } \\
\text { documentos estão a seguir: Guia Alimentar: http://portalsaude.saude.gov.br/ .../Guia-Alimentar-para-a-pop Guia Alimentos } \\
\text { Regionais Brasileiros: http://189.28.128.100/.../livro_alimentos_regionais_brasileir... Aproveitem! }\end{array}$ \\
\hline $11 / 092016$ & Receitas & $\begin{array}{l}\text { Preciso de ajuda:: } 0 \text { niver de } 2 \text { anos da minha pequena está chegando, e queria a ajuda de vocês para montar } \\
\text { o cardápio, me ajudem com dicas e receitas por favor. } \\
\text { Respostas: Melissa Priel fiz pra minha filha que completou agora } 3 \text { anos algo muito simples - convidei amiguinhos da } \\
\text { escolinha - } 7 \text { amigos - fiz tudo simples - bexigas+ faixas+ toalha de } \\
\text { bolinhas - fiz tortas de liquidificador, macarrão, pepinos e tomates cortadinhos ( tomate cereja) ,pão e pates como tehina } \\
\text { e atum, suco de maca integral, picolé caseiro, bolinhas de tâmara e bolo mousse feito com purê de maça. C.D.B: } \\
\text { Espetinhos de frutas bem coloridas, sanduiche de carne louca, quindim caseiro, canudinhos com frango, cenoura e } \\
\text { maionese caseira }\end{array}$ \\
\hline
\end{tabular}




\begin{tabular}{|l|l|l|}
$24 / 012017$ & $\begin{array}{l}\text { D.A: Gurias... minha filha vai completar 1 ano e ela tem baixo peso (7400g e } 71 \text { cm). } \\
\text { alimentares } \\
\text { Estou tentando fazer com que ela ganhe peso saudavelmente. Ela é APLV e alérgica também a soja, ovo e } \\
\text { amendoim. Tenho dado após a fruta, um (falso) pão de queijo de batata ou aipim e queria dar pão caseiro tb. Minha } \\
\text { dúvida: Na única receita que consegui sem leite, soja e ovos, vai } 3 \text { colheres de açúcar mascavo orgânico... algum } \\
\text { problema usar açúcar no pão? Ela nunca comeu nada com açúcar e mama em livre demanda. Thais Ventura e } \\
\text { Karine Costa Durães help? } \\
\text { Resposta: R.C: Nem todo açúcar do pão é consumido durante a fermentação. Parte dele compõe o sabor sim. Você } \\
\text { faz parte de grupos de apoio? Recomendo que entre no MFAL e no Receitas APLV. } \\
\text { Lá encontra muitas receitas sem alérgenos para ajudar na alimentação dela. A página Menu Bacana também tem } \\
\text { dica para alergias. } \\
\text { D.H: Capricha no abacate (banana c abacate) e coco ralado fresco, dá pedaços de coco pra ficar roendo! Purê de } \\
\text { inhame batido com fruta! Rodelas de batata doce cozida! Usa gordura boa na } \\
\text { comida dela: Óleo de coco, óleo de abacate. Coloca painço descascado na sopa, pode fazer frutinha cozida com } \\
\text { painço também. Mingau de aveia c banana, canela, água ou maçã ralada, pera ralada! }\end{array}$ \\
\hline
\end{tabular}

Fonte: Elaborado pelas autoras.

Conforme Ferreira (2007), a incidência de alergias alimentares vem aumentando consideravelmente, principalmente na faixa etária pediátrica. Isso gera um impacto negativo financeiro, médico e na qualidade de vida das crianças e de seus pais, principalmente em mães que estão em aleitamento materno. Acredita-se que o consumo exagerado de alimentos cada vez mais ultraprocessados e industrializados vem piorando esse quadro globalmente. Segundo Sicherer (2011 apud SILVA, 2016, p. 12), "Alergias alimentares afetam de $2 \%$ a $10 \%$ da população mundial (SICHERER, 2011). No Brasil, não há pesquisas nacionais, nem registros nos sistemas de informação do Ministério da Saúde sobre o número de crianças com alergias alimentares e sua prevalência."

$\mathrm{O}$ tratamento das alergias alimentares consiste em eliminar e excluir alérgenos específicos, sendo essa a única forma de manejo eficaz atualmente. No caso das alergias à proteína do leite de vaca, isso se torna extremamente limitante e observa-se que as mães buscam grupos de apoio nas redes sociais para trocar informações, experiências e atualidades relacionadas ao tema. As redes sociais e o apoio social gerado pelas mesmas permite que a condição da criança seja mais facilmente enfrentada pela família, gerando um equilibrio familiar e com maior capacidade de superar as adversidades que podem ocorrer durante a doença.

\subsubsection{Mundo BLW}

Perfil do Instagram com 31.500 seguidores com o objetivo de dar dicas, informações e experiências sobre o método de introdução alimentar BLW. Nela predominam postagens de vídeos demonstrativos, mas compartilha também muitas imagens, relatos e textos narrativos. Como é um perfil, gera pouca interatividade entre os participantes e pouca comunicação do autor com os usuários, consequentemente, não gera discussões ou levanta debates. Os usuários adquirem conhecimento de uma forma mais passiva, principalmente, através de vídeos demonstrativos sobre a prática do método, em sua maioria.

Quadro 8 - Postagens selecionadas no perfil "Mundo BLW"

\begin{tabular}{|c|c|c|}
\hline Data & Assunto & Conteúdo \\
\hline \multirow{2}{*}{$\begin{array}{l}21 / 11 \\
2016\end{array}$} & \multirow{2}{*}{$\begin{array}{l}\text { Oferta de } \\
\text { alimentos de } \\
\text { forma segura }\end{array}$} & $\begin{array}{l}\text { Vídeo da autora cortando milho seguido de texto: E é assim que ofereço milho até hoje pra Olivia (que está com } 2 \text { anos e } \\
5 \text { meses)!Cortando grãos dessa forma, saem até com a gengiva! Já ficam cortados ao meio e diminuem MUITO a chance } \\
\text { de engasgo! } 41 \text { comentários e } 6.432 \text { visualizações }\end{array}$ \\
\hline & & $\begin{array}{l}\text { G: Qual tempo de cozimento dos legumes e milho? As vezes cozinho demais. Resposta da autora: cozinho o milho por } \\
\text { 40minutos na panela de pressão elétrica! }\end{array}$ \\
\hline $27 / 09$ & BLW & Vídeo de um bebê se alimentando BLW seguido de texto: Primeira vez com um alimento! \\
\hline 2016 & & $\begin{array}{l}\text { Iniciando o BLW... Sarah está com } 6 \text { meses! Reparem como ela senta, como ela se mantém equilibrada e não tomba para } \\
\text { os lados! Como ela tem o interesse pelo alimento e ela vai em direção a ele! Como já segura o alimento e leva na boca! }\end{array}$ \\
\hline
\end{tabular}




\begin{tabular}{|c|c|c|}
\hline & & $\begin{array}{l}\text { Bebês nessa fase não tem controle de abrir e fechar as mãos coordenadas! Eles pegam o alimento e ficam com o punho } \\
\text { fechado! É importante que nesse começo os alimentos sejam oferecidos em forma de palitos! Para que sobre fora da } \\
\text { mãozinha e eles possam comer! É importante não cozinhar demais porque ainda não tem controle da força! O BLW vai } \\
\text { ajudar muito com isso! Eles aprenderão dia a dia qual força usar para cada alimento! É incrivel ver um bebê comer pela } \\
\text { primeira vez! É incrivel ver essa relação sendo construída! Em breve mais novidades! Boa sorte e conte com a gente } \\
\text { nessa jornada@ @diaadiademamae. Sarah, divirta-se!" } 122 \text { comentários e } 8.447 \text { visualizações }\end{array}$ \\
\hline $11 / 01$ & Açúcar & Vídeo de criança recusando bolo de chocolate seguido do texto: Por que é tão importante adiar a \\
\hline 2017 & & $\begin{array}{l}\text { introdução de açúcar e sabores muito doces na vida dos filhos? Muitas pessoas não entendem ou não sabem o normal, } \\
\text { porque a maioria de foi criado com açúcar, temos os "sabores da infância" e estamos aí vivos e cheio de saúde né? Na } \\
\text { verdade a importância de adiar é pra formar o paladar, um paladar com mais abrangência de sabores, menos rejeição } \\
\text { e pessoas menos exigentes, porque é importante pra nossa saúde comer bem e variado! } 0 \text { açúcar e sabores doces } \\
\text { viciam o paladar... Por isso é difícil adultos criados com açúcar deixar de comer, também vivemos uma cultura onde } \\
\text { açúcar é confundido com amor, então privar seu filho de açúcar é privar de "felicidade", o que não é verdade! É } 1 \text { ano } \\
\text { e meio de "trabalho" oferecendo ao seu filho comida variada e saudável, sem a de açúcar pra que depois se torne uma } \\
\text { criança menos exigente de doces, saudável, com um paladar formado a poder comer coisas doces de forma balanceada! } \\
\text { A maioria das crianças que não tiveram açúcar na primeira infância rejeitam coisas muito doces... E elas não estão } \\
\text { perdendo nada! Apenas ganhando em saúde! Esse vídeo é da Olivia, de } 2 \text { anos e } 3 \text { meses! Ela come açúcar? Come de } \\
\text { vez em quando desde os } 18 \text { meses... Ela prefere uma maçã a chocolate! Preferiu um pepino a esse bolo! Acho que não } \\
\text { preciso entrar em detalhes sobre os malefícios da ingestão de açúcar no organismo, você encontra em qualquer pesquisa } \\
\text { no Google. Esse texto é pra dar forca familia que escolheu deixar o açúcar pra depois e sofre com críticas! Saiba que } \\
\text { você tá no caminho certo! Planta uma sementinha pra colher na frente! Assim é com os filhos! } 66 \text { comentários e } \\
6662 \text { visualizações }\end{array}$ \\
\hline
\end{tabular}

Fonte: Elaborado pelas autoras.

Ao analisar as postagens, nota-se que vídeos e textos apresentam conteúdo de qualidade e atuais. Estimula-se o consumo consciente e traz ideais concordantes com a literatura. Rinaldi et al. (2008) destaca a importância do consumo equilibrado de alimentos açucarados e hipercalóricos, pois esses tipos de alimentos estão comprovadamente relacionados ao aumento da obesidade e comorbidades. Nota-se que as crianças que se alimentam de quantidade exagerada desses alimentos tem a tendência de consumir frutas, hortaliças e leguminosas de forma insuficiente e apresentam, ainda, a tendência de trocar refeições por bebidas lácteas com alta concentração de açúcar e menor concentração de cálcio, além de uma ingestão exagerada de alimentos prontos (industrializados e congelados) e refrigerantes. Rinaldi et al. (2008, p. 274) conclui que: "Estes hábitos sinalizam para a necessidade de trabalho de educação alimentar envolvendo o núcleo familiar, os órgãos governamentais e os meios de comunicação".

\subsubsection{Nutri infantil}

O perfil do Instagram da autora que é uma nutricionista pediátrica apresenta 115.000 seguidores. Posta diversas imagens, seguidas de orientações de quando, como e quais alimentos oferecer, indicações, explicações e contraindicações relacionados à nutrição infantil, na maioria das vezes, colocando a fonte onde a orientação (Academia Americana de Pediatria, Guia Alimentar do Ministério da Saúde, Associação Brasileira de Nutrologia). Também esclarece dúvidas e responde os participantes, através dos comentários do perfil, porém também não costuma gerar discussões entre os participantes. Novamente nota-se um perfil de participantes mais passivos em relação à aquisição do conhecimento.

Quadro 9 - Postagens selecionadas no perfil "Nutri Infantil"

\begin{tabular}{|c|c|l|}
\hline Data & Assunto & \multicolumn{1}{c|}{ Conteúdo } \\
\hline \multirow{2}{*}{$13 / 10$} & Coles-terol & $\begin{array}{l}\text { É necessário preocupar-se com colesterol na infância? A resposta correta é SIM. Estudos de necrópsia após morte } \\
\text { inesperada em crianças e jovens demonstraram que a presença e a gravidade de lesões ateroscleróticas correlacionam-se } \\
\text { positiva e significativamente com os fatores de risco cardiovascular. O período de maior progressão das estrias gordurosas } \\
\text { para placas fibrosas ocorre a partir dos 15 anos. - A partir dos 2 anos, crianças com alterações nutricionais, dificuldades } \\
\text { alimentares, sedentárias, com história familiar positiva para doença cardiovascular, obesidade e síndrome metabólica, } \\
\text { que têm alguma doença crônica associada, ou que fazem uso de determinados medicamentos, todos esses devem ter o } \\
\text { perfil lipídico e triglicerídeos avaliados. Após comprovada alteração, o tratamento dietético e início de atividade física são } \\
\text { necessários para a prevenção de eventos cardíacos futuros. } \\
\text { - Para os maiores de 8 anos, independente de fatores de risco, a avaliação deve ser de rotina, devendo-se atentar para } \\
\text { o colesterol não-HDL (ruim) e HDL (bom), que fazem a triagem para dislipidemia. Se alterados, confirmar com perfil } \\
\text { completo + triglicerídeos, com 12h de jejum, instituindotratamento. - CONCLUSÃO: vamos manter o nosso hábito alimentar } \\
\text { saudável! O coração das nossas crianças agradece! Boa tarde, queridos! 142 curtidas e 9 comentários }\end{array}$ \\
\hline
\end{tabular}




\begin{tabular}{|c|c|c|}
\hline $\begin{array}{l}28 / 09 \\
2016\end{array}$ & Açúcar & $\begin{array}{l}\text { O paladar do bebê começa a ser formado na barriga da mamãe. Por isso cuidado com o que as gravidinhas estão ingerindo } \\
\text { por ai! A necessidade do açúcar é de nós adultos e não do bebê! Pensem bem antes de sairem consumindo uma quantidade } \\
\text { absurda de açúcar. } \\
\text { O açúcar branco é considerado caloria vazia, isso quer dizer que ele não agrega nenhum nutriente para nosso organismo. E } \\
\text { essa caloria vazia pode ser transformada em excesso de peso, câncer e diabetes futuramente. - O açúcar "tira"o sabor real } \\
\text { dos alimentos e ele tem o poder de "viciar" o bebê ou a criança com aquele saborzinho doce. E quando outro alimento for } \\
\text { oferecido na forma natural sem adoçar, o bebê irá rejeitarimediatamente. - Por volta de } 1 \text { ano e meio e } 3 \text { anos a criança se torna } \\
\text { mais seletiva. E para as que estão acostumadas a comer maior parte das refeições com açúcar, os pais irão passar por grandes } \\
\text { dificuldades. Pois será mais difíil a introdução de outros alimentos. - Até os dois anos de idade, o recomendável é não dar } \\
\text { açúcar nenhum para o bebê, o ideal é que este hábito se prolongue o maior tempo possível. O melhor é optar por alimento in } \\
\text { natura, sempre ter em casa frutas e verduras e excluir das compras refrigerantes, balas, gelatinas, achocolatados, sucos em } \\
\text { pó e de caixinha, chocolates, sucrilhos, pirulitos, bolinhos industrializados, entre outros. } 1213 \text { curtidas e } 135 \text { comentários }\end{array}$ \\
\hline $\begin{array}{l}17 / 02 \\
2017\end{array}$ & Ovo & $\begin{array}{l}\text { O ovo é considerado um alimento com potencial alergênico. O ovo (clara) era excluído do plano alimentar do bebê (6 meses até } \\
1 \text { ano). Porém hoje a orientação da Sociedade Brasileira de Pediatria (SBP) é que bebês a partir de } 6 \text { meses já estão liberados } \\
\text { para consumir clara e gema. } \\
\text { Segundo estudo, observaram que quando introduzido o ovo a partir dos } 6 \text { meses, o risco de alergia diminuiu e se introduzido } \\
\text { depois de } 1 \text { ano o risco aumenta. O ovo é uma excelente fonte de colina. A colina é um nutriente que ajuda no desenvolvimento } \\
\text { cerebral, memória e concentração. O ovo caipira é mais saudável do que o convencional, pois possui maior quantidade de } \\
\text { carotenoides que tem importante ação antioxidante e evita a degeneração macular. Ele não deve ser consumido cru ou com a } \\
\text { gema mole, pois há o risco de infecções intestinais. } 616 \text { curtidas e } 122 \text { comentários. }\end{array}$ \\
\hline
\end{tabular}

Fonte: Elaborado pelas autoras.

Apesar de ainda hoje existirem bastante mitos em relação ao ovo, sabe-se que suas proteínas possuem alto valor biológico e apresentam boa digestibilidade. Alimentos potencialmente alergênicos devem já ser introduzidos a partir do sexto mês de vida, pois, nesse período, a criança está na janela imunológica e possui maior aquisição de tolerância e redução no risco de alergenicidade. Segundo Weffort et al. (2012, p. 30),

O ovo além de excelente fonte proteica e de cofatores de alta eficiência nutricional, tem baixo custo e sua adoção deve ser incentivada na alimentação complementar. Para garantir a não contaminação por bactérias enteropatogênicas, o ovo deve sempre ser consumido com a clara e a gema cozidas. Sempre que possível, diversificar o tipo de proteína animal consumido ao longo da semana, proporcionando maior variedade de nutrientes e micronutrientes essenciais para o desenvolvimento nesta fase, como ferro e zinco.

\subsubsection{Maternutri}

Também é um perfil de uma nutricionista na rede social Instagram e possui 46.100 seguidores. As postagens são, em sua maioria, na forma de imagens e o conteúdo predominante é sobre o que oferecer e cardápios alimentares. O foco do perfil não é o método BLW e sim, a alimentação de qualidade. A autora nem sempre especifica a fonte das informações apresentadas, e, como nos demais perfis, as postagens não geram trocas de conteúdos.

Quadro 10 - Postagens selecionadas no perfil "Maternutri"

\begin{tabular}{|c|c|c|}
\hline Data & Assunto & Conteúdo \\
\hline $30 / 102016$ & $\begin{array}{c}\text { Água de } \\
\text { Côco }\end{array}$ & $\begin{array}{l}\text { Posso oferecer água de côco para meu bebê de } 6 \text { meses? } \\
\text { Sim MAS temos que ter cuidado com a quantidade de sais minerais desse alimento } \\
\text { (como pode ver na foto, é fonte de: magnésio, potássio, fósforo e sódio - Taco, 2011). } \\
\text { Todos estão em pouca quantidade mas para um bebê de } 6 \text { meses precisa de muito pouco desses minerais } \\
\text { e com a alimentação sólida pode ultrapassar necessidades diárias da criança sobrecarregando os rins } \\
\text { desse serzinho. Portanto, deve-se restringir a quantidade e a frequência a ser oferecido para os bebês até } 1 \text { ano de } \\
\text { idade, pelo menos!! Quanto posso oferecer } 50 \text { ml de } 1 \text { a } 2 \text { X por semana. E ainda tem outro problema de água de } \\
\text { côco: Ela é DOCE, assim as crianças começam a preferir o côco em detrimento de ÁGUA + PURA } 305 \text { curtidas } \\
\text { e } 45 \text { comentários } \\
\text { O calor está chegando e com elas um monte de frutas deliciosas É por isso temos que ficar de olho na safra. Você } \\
\text { sabia que frutas da estação tem várias vantagens? Elas são mais baratas. Então você consegue economizar. São } \\
\text { mais ricas nutricionalmente. E, no geral, contém menos agrotóxicos. Prefira sempre comprar vegetais e frutas em } \\
\text { feiras, costuma ser mais barato. Então, se não dar para comprar o orgânico, pelo menos prefira as frutas da época. No } \\
\text { mês de outubro, além dessas que estão na foto, ainda temos: - amora; - maracujá; - maçã; - peras; - nozes. Na hora } \\
\text { das compras, prefira sempre produtos agroecológicos e da agricultura familiar. Fonte: Ministério do Desenvolvimento } \\
406 \text { curtidas e } 14 \text { comentários }\end{array}$ \\
\hline $11 / 112016$ & Alimen-tação e & $\begin{array}{l}\text { Foto de um cardápio escolar seguido de texto: Aquele momento que a nutri pira: ao ver esse cardápio tenho certeza } \\
\text { que devemos mudar urgentemente essa associação de guloseimas, doces e porcarias }\end{array}$ \\
\hline
\end{tabular}




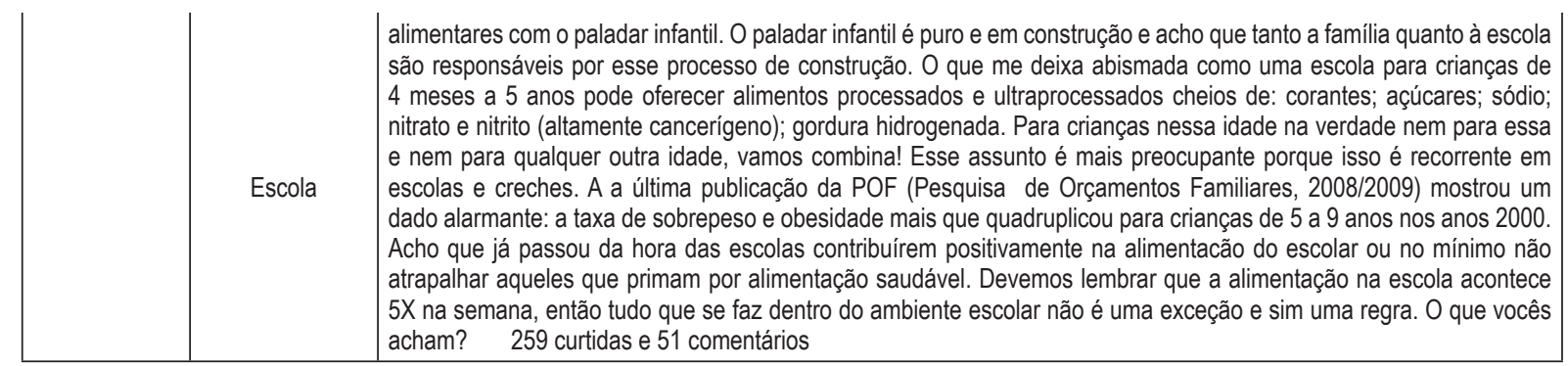

Fonte: Elaborado pelas autoras.

Mesmo com todas as campanhas e conscientização sobre nutrição infantil, a situação dos hábitos alimentares infantis dos brasileiros ainda é preocupante, como alerta a autora da postagem. Estudo descritivo de prevalência realizado na Paraíba demonstrou que as maiores prevalências de desvios antropométricos foram de sobrepeso e baixa estatura (PEDRAZA, 2016). Nas últimas décadas, tem se observado uma ingestão muito elevada de gordura, sódio e açúcar e diminuição da ingestão de alimentos ricos em nutrientes, como fibras, verduras e frutas, gerando um grande impacto no sobrepeso infantil.

Vieira et al. (2017), em estudo multicêntrico transversal, avaliou crianças que frequentam creches públicas e privadas no Brasil, e identificou que, principalmente as crianças matriculadas em creches privadas tinham um padrão alimentar caracterizado como "lanches", que é basicamente composto de alimentos rápidos de preparo e de baixa qualidade nutricional como doces, tortas, sanduíches e refrigerantes, ricos em açúcar e com alta carga calórica e glicêmica. E as crianças que frequentam creches públicas tiveram menor ingestão desse tipo de alimento, o que pode ser atribuído ao Programa Nacional de Alimentação Escolar (PNAE) que preconiza a redução de alimentos processados, ricos em gordura, sal e açúcar em refeições infantis. Vieira et al. (2017, p. 53) afirma que:

Dessa forma, a creche desempenha um papel fundamental na ingestão alimentar de crianças, cria oportunidades para que elas ampliem o repertório de alimentos consumidos e construam uma referência de alimentação saudável, pelo modo como estão expostas a uma grande variedade de alimentos ricos em nutrientes em refeições escolares. Além disso, as creches apoiam a importância da educação nutricional e políticas públicas para garantir a qualidade das refeições escolares.

\subsubsection{Tá na hora do papá}

No período analisado, "Tá na hora do papá" foi o perfil do Instagram que apresentou maior número de postagens (290), com predomínio do tipo imagem. Aautora éfonoaudióloga e posta suas experiências com IA participativa e BLW e o conteúdo é semelhante ao da página no Facebook. O perfil interage com os usuários e responde as dúvidas, através dos comentários em cada postagem. O conteúdo se baseia, principalmente, na experiência e prática da autora.

Quadro 11 - Postagens selecionadas no perfil Tá na hora do papá

\begin{tabular}{|c|c|c|}
\hline Data & Assunto & Conteúdo \\
\hline $24 / 11$ & Aleita- & Tetê power! www.conalco.com.br\#Repost@pediatriadescomplicada \\
\hline 2016 & mento materno & $\begin{array}{l}\text { Palestra do Dr. Cesar Victora, sobre a importância do leite materno e o seu impacto na saúde da criança, da mãe, impacto social } \\
\text { e também econômico! O que sabemos em termos de ciência do leite materno é apenas a ponta do iceberg. Os benefícios } \\
\text { do aleitamento materno são enormes, inúmeros e ainda pouco conhecidos. Ainda há muito para se descobrir. Se o aleitamento } \\
\text { materno fosse inventado hoje, essa pessoa mereceria receber } 2 \text { prêmios Nobel, o de medicina e o de economia. Engana-se quem } \\
\text { acredita que amamentação é coisa de "país não desenvolvido" ou ainda "países em desenvolvimento". O impacto do aleitamento } \\
\text { materno na economia de um país é marcante. O aleitamento materno promove um ganho no PIB de } 300 \text { bilhões de dólares, o } \\
\text { que corresponde a 0,5\% do PIB mundial!! Em suma, a culpa NÃO é das mães, mas de toda sociedade que precisa se mobilizar } \\
\text { em prol da amamentação! Isso em todos os níveis! Profissionais da saúde, políticos, governantes, família e toda a Sociedade!!! } \\
\text { Quem vem com a gente nessa luta? Sobre a série de amamentação do Lancet: bit.ly/28WZiRJ Dra Kelly Marques Oliveira www. } \\
\text { pediatriadescomplicada.com Pediatra e Consultora Internacional de Amamentação (IBCLC) } 229 \text { curtidas e } 6 \text { comentários }\end{array}$ \\
\hline $15 / 10$ & Choro & Foto dos filhos dormindo juntos seguido de texto: Uma hora depois. Não sei se como, durmo ou tomo \\
\hline
\end{tabular}

Cad. Pesq., São Luís, v. 25, n. 2, p. 243-265, abr./jun. 2018. 


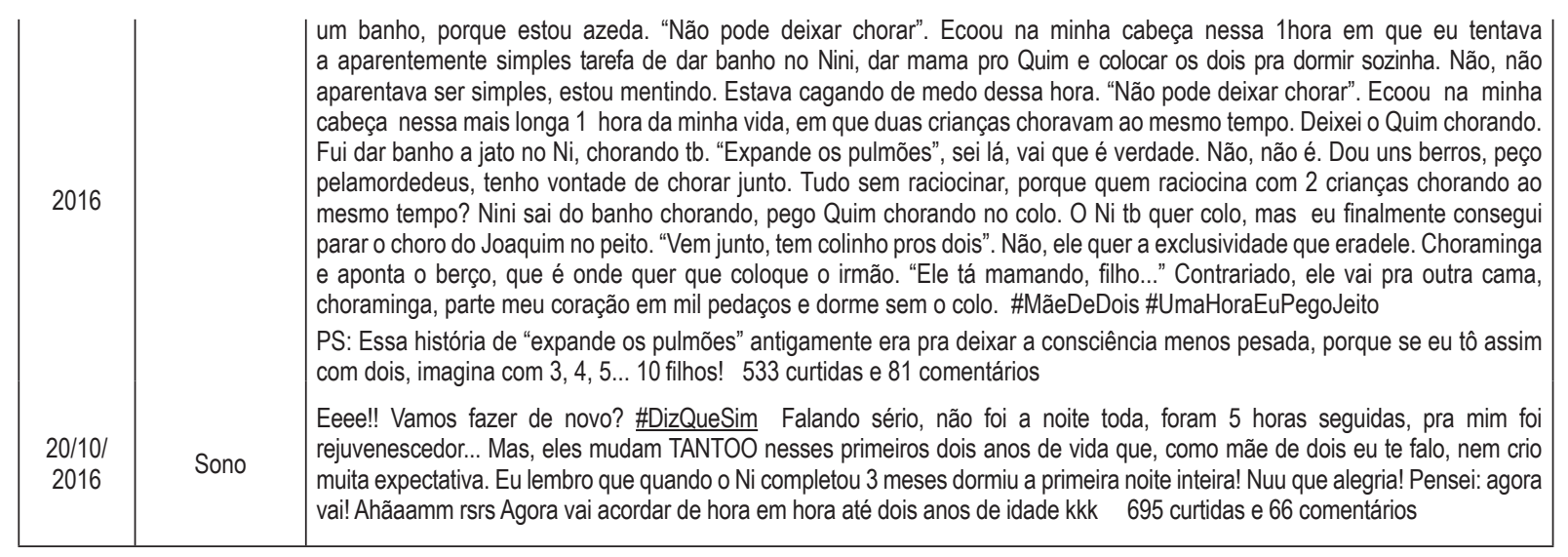

Fonte: Elaborado pelas autoras.

É de conhecimento geral que o contexto familiar se modifica após o nascimento dos filhos e exige que a família se reestruture para lidar com as circunstâncias que surgem nesse período. O nascimento de um bebê pode ser extremamente desgastante em decorrência de novos hábitos e rotinas que surgem na família. Privação de sono, aleitamento materno, atenção praticamente exclusiva a esse novo integrante pode ser um evento estressante, principalmente, para as mães.

Em decorrência disso, Rapoport e Piccinini (2006) cita que uma rede de apoio social bem solidificada é importante e facilitadora para uma maternagem responsável, melhorando a qualidade de vida tanto dos pais quanto do bebê. Exemplo disso é que todos sabem que bebês não costumam dormir a noite toda no início do primeiro ano, porém, na prática, poucos entendem o que é acordar várias vezes de madrugada e perder o ritmo cotidiano diário, com privação de várias coisas que eventualmente faziam.

Nota-se que as postagens mais curtidas no período analisado foram exatamente as quais a autora fazia um compartilhamento do seu dia a dia da maternidade, expondo que seu filho pequeno ainda dormia muito mal e que a autora estava cansada. Muitos usuários curtiram justamente por esse post aproximá-los da maternidade real, fazendo com que se sentissem pertencentes a um grupo e que não estavam sozinhos, passando por situações, algumas vezes, desgastantes. Novamente se nota a formação de uma rede, um elo social que ligam pessoas com interesses e dificuldades em comum, formando uma comunidade.

\section{CONSIDERAÇÕES FINAIS}

O objetivo central da pesquisa era mapear os conteúdos presentes em redes sociais sobre a nutrição infantil e o BLW, a fim de verificar como funcionam enquanto comunidades de aprendizagem. Durante a análise das respostas, observou-se que muitos familiares citaram onde buscaram informações ou quem os orientou sobre o início da introdução alimentar. Participantes com informações adequadas (seguindo recomendações da OMS, SBP e literatura científica) e atualizadas sobre introdução alimentar, citaram que adquiriram esse conteúdo nessas comunidades de aprendizagem inseridas nas redes sociais. Outros assuntos citados durante a análise foram: aleitamento materno, desmame, alimentação oferecida pelas escolas, locais onde poderiam obter informações atualizadas e de qualidade, ideias de alimentos a serem oferecidos e troca de receitas, alimentos industrializados e alergias alimentares.

Interessante pontuar que as mães buscam nas comunidades uma rede de apoio que incentiva, demonstra empatia e dá suporte para manutenção de hábitos alimentares saudáveis, cuja importância foi citada 14 vezes. Muitos participantes relataram que se não tivessem buscado conhecimentos ou experiências em comunidades de redes sociais, não teriam tido sucesso no aleitamento materno. A maioria das respostas foi de acordo com o preconizado pela OMS e SBP, seguindo orientação de não liquidificar alimentos, iniciar após os 6 meses ou quando o bebê conseguir sentar sem apoio, 
ofertar variedade de fibras e proteínas, não usar sal até 1 ano e evitar açúcar até os 2 anos de idade.

As comunidades de aprendizagem exploradas na pesquisa se organizam como espaços favoráveis ao compartilhamento de informações e experiências entre pessoas que se interessam por nutrição infantil e método BLW, de diferentes idades e grupos sociais, a maioria mães buscando orientação. Essas comunidades têm gestores que atuam como membros ativos que organizam e dinamizam o grupo promovendo a interação. Algumas pessoas participam para tirar alguma dúvida ou são profissionais da saúde interessados na temática. Situações pessoais de familiares que estão iniciando a introdução alimentar são compartilhadas em um processo de ajuda recíproca, sendo que esse tipo de postagem motiva os usuários em comentários e curtidas. As comunidades de aprendizagem sobre nutrição infantil apresentam número crescente de participantes, geram conteúdo de qualidade, troca de informações e conteúdos concordantes com as principais diretrizes da Sociedade Brasileira de Pediatria, Academia Americana de Pediatra e Organização Mundial de Saúde. Após análise do conteúdo das redes sociais, considera-se que essas comunidades são locais adequados onde se podem buscar informações.

Conclui-se que as pessoas têm buscado cada vez mais conhecimentos nas comunidades de aprendizagem das redes sociais em uma aprendizagem coletiva, deixando de obter informações exclusivamente com os profissionais de saúde. O conhecimento do pediatra continua sendo importante para as famílias, porém não são conhecimentos exclusivos. Nota-se que os familiares vão averiguar essas informações na internet, procurar artigos e discutir condutas nesses grupos virtuais. Assim, se conclui que os ambientes virtuais podem ser empregados como facilitadores das práticas em nutrição infantil e do método BLW.

Inúmeras são as possibilidades de desdobramentos dessa pesquisa para trabalhos futuros. É possível citar como encaminhamento a elaboração de uma comunidade virtual de aprendizagem considerada ideal, com moderadores da área da saúde composto por nutricionistas e pediatras com fóruns de discussões, ampla participação de pais e familiares, esclarecimento de dúvidas e postagens somente com conteúdo atualizado e com evidências científicas. Outro tema para pesquisa futura é o desenvolvimento de um aplicativo médico sobre nutrição infantil, introdução alimentar e BLW para utilização de pediatras e seus pacientes. Por fim, ao considerar os pontos acima, deseja-se que os resultados obtidos nessa pesquisa sirvam de apoio e incentivo aos pediatras e demais profissionais de saúde para compreenderem a importância das redes sociais como um instrumento que auxilia de forma prática e eficiente na educação em saúde e na construção de conhecimentos coletivos significativos e atualizados.

\section{REFERÊNCIAS}

ABREU, N. R. de. Comunidades virtuais como fonte de informação para estratégias mercadológicas. 2006. Tese (Doutorado em Administração) - Universidade Federal de Lavras, Lavras -MG, 2006.

ALAVARCE, D. C.; PIERIN, A. M. G. Development of educational hypermedia to teach an arterial blood pressure measurement procedure. Revista da Escola de Enfermagem da USP, v. 45, n. 4, p. 933-938, 2011.

ALBUQUERQUE, A. A. D. Saberes e práticas de docentes no uso de TIC na educação em saúde. 2013. Dissertação (Mestrado em Ensino na Saúde) Faculdade de Medicina, Universidade Federal de Alagoas, Maceió, 2013.

BARCELOS, G. T.; PASSERINO, L. M.; BEHAR, P. A. Redes sociais e comunidades: definições, classificações e relações. Politics, n. 2000, p. 36-40, 2010. 
BOY, J. D.; UITERMARK, J. How to study the city on instagram. PLoS One, v.11, n.6, 2016. Disponível em: <http://pesquisa.bvsalud.org/portal/resource/pt/mdl-27336728>. Acesso em: 02 nov. 2016.

BRUNO, A. Educação formal, não formal e informal: da trilogia aos cruzamentos, dos hibridismos a outros contributos. Mediações - Revista OnLine da Escola Superior de Educação do Instituto Politécnico de Setúbal, v. 2, n. 2, 2014. Disponível em: <http://mediacoes.ese.ips.pt/ index. php/ mediacoesonline/article/view/68/pdf_28>. Acesso em: 28 jul. 2017.

CAETANO, M. C. et al. Complementary feeding: inappropriate practices in infants. Revista Chilena de Pediatria, v. 83, n. 5, p. 503, 2012.

CAMERON, S. L.; HEATH, A.-L. M.; TAYLOR, R. W. How feasible is baby-led weaning as an approach to infant feeding?: review of the evidence. Nutrients, v.4, n.11, p.1575-1609, Nov. 2012.

CANAVILHAS, J. A saúde na blogosfera portuguesa. Covilhã-PT: UBI, 2005. Disponível em: <http://www.bocc.ubi.pt/pag/canavilhas-joao-blogues-saude.pdf>. Acesso em: 02 nov. 2016.

CARVALHO, C. A. de et al. Food consumption and nutritional adequacy in brazilian children. Revista Paulista de Pediatria, São Paulo, v. 33, n. 2, p. 211-221, abr./jun. 2015.

CASTRO, R.C.F. Impacto da Internet no fluxo da comunicação científica em saúde. Rev. Saúde Pública, São Paulo, v. 40, nesp., p. 57-63, Aug. 2006. Disponível em: <http://www.scielo.br/scielo.php?script= sci_arttext\&pid=S0034-89102006000400009\&lng=en\&nrm=iso>. Acesso em: 23 maio 2017.

D'ANDREA, E. et al. Baby-led weaning: a preliminary investigation. Canadian Journal of Dietetic Practice and Research, v. 77, n. 2, p. 72-77, 2016.

FANGUPO, L. J. et al. A baby-led approach to eating solids and risk of choking. Pediatrics, v. 138, n. 4, 2016.

FERREIRA, A. V. S.; GARCIA, E. Suporte básico de vida. Revista da Sociedade de Cardiologia do Estado de São Paulo, v. 11, n. 2, p. 214-225, 2001.

FERREIRA, C.T.; SEIDMAN, E. Alergia alimentar: atualização prática do ponto de vista gastroenterológico. J. Pediatr. (Rio J.), Porto Alegre, v. 83, n. 1, p. 7-20, Feb. 2007. Disponível em: <http://www.scielo.br/scielo.php?script=sci_arttext\&pid=S0021-75572 007000100004\&ln$\mathrm{g}=\mathrm{en} \& \mathrm{nrm}=\mathrm{iso}>$. Acesso em: 26 maio 2017.

FISBERG, M.; TOSATTI, A. M.; ABREU, C. L. A criança que não come: abordagem pediátrico-comportamental. In: CONGRESSO INTERNACIONAL SABARÁ DE ESPECIALIDADES PEDIÁTRICAS, 2., 2014, São Paulo. Anais... São Paulo: Blucher Medical Proceedings, 2014.

MCLAWHORN, A. S. et al. Social media and your practice: navigating the surgeon-patient relationship. Curr. Rev. Musculoskelet. Med., v. 9, n. 4, p. 487-495, Dec. 2016.

MINAYO, M. C. de S. O desafio do conhecimento: pesquisa qualitativa em saúde. São Paulo: HUCITEC, 2007.

MONTARDO, S.P. Comunicação como forma social: proposta de interseção entre a comunicação e a cibercultura. In: CONGRESSO BRASILEIRO DE CIÊNCIAS DA COMUNICAÇÃO, 28., 2005, Rio de Janeiro. Rio de Janeiro: UERJ, 2005.

PADOVANI, A. R. Introdução alimentar participativa: respeitando o tempo do bebê. 2015. Disponível em: <https://conalco.com.br/wp- content/uploads/2015/05/ebook-IA-ParticipATIVA. pdf>. Acesso em: 26 maio 2017. 
PEDRAZA, D. F. Saúde e nutrição das crianças assistidas em creches públicas do município de Campina Grande, Paraíba. Cad. Saúde Colet., Rio de Janeiro, v. 24, n. 2, p. 200-208, 2016. Disponível em: <http://www.scielo.br/pdf/cadsc/v24n2/1414-462X-cadsc-24-2-200.pdf>. Acesso em: 26 maio 2017.

POSSOLLI, G. E.; NASCIMENTO, G. L. Contribuições do facebook para formação médica: estudo de caso dos cursos de medicina de Curitiba. Revista Educação e Cultura Contemporânea, v. 13, n. 31, p. 221-252, 2016. Disponível em: <http://periodicos.estacio.br/ index.php/reeduc/article/ view/1942/1148>. Acesso em: 26 maio 2017.

RAPLEY, G. Guia para implementação de uma abordagem de introdução de alimentos sólidos guiada pelo bebê. 2008. Disponível em: «www.rapleyweaning.com>. Acesso em: 26 maio 2017.

RAPOPORT, A.; PICCININI, C. A. Apoio social e experiência da maternidade. Rev. Bras. Crescimento Desenvolv. Hum., São Paulo, v. 16, n. 1, p. 85-96, abr. 2006. Disponível em: <http:// pepsic.bvsalud.org/scielo.php?script=sci_arttext\&pid=S0104-12822006000100009>. Acesso em: 30 maio 2017.

RINALDI, A. E. M. et al. Contribuições das práticas alimentares e inatividade física para o excesso de peso infantil. Rev. Paul. Pediatr., v. 26, n. 3, p. 271-277, 2008. Disponível em: <www.scielo.br/pdf/rpp/v26n3/12>. Acesso em: 30 maio 2017.

SANTOS, N. B. Educação e promoção da saúde na internet. Cad. Mídia Saúde Pub., v. 2, n. 1, p. 37-48, 2007.

SILVA, A.M.P. Ciberantropologia: o estudo das comunidades virtuais. 2004. Disponível em: <http:// www.bocc.uff.br/pag/silva-adelina-ciberantropologia.pdf> Acesso em: 30 maio 2017.

SILVA, R. L. F. Alergias alimentares: uma revisão integrativa com foco sobre as proteínas do leite e do ovo. 2016. Trabalho de Conclusão de Curso (Graduação em Nutrição)- Universidade Federal do Rio Grande do Norte, Natal, 2016. Disponível em: <https://monografias.ufrn. br/jspui/bitstream/123456789/3399/1/ RayneLFS_Trabalho\% 20de\%20Conclusão\%20de\%20 Curso>. Acesso em: 30 maio 2017.

SOARES, M. C. Internet e saúde: possibilidades e limitações. Revista Textos de la CiberSociedad, n. 4, 2004. Disponível em: <http://www.cibersociedad.net>. Acesso em: 30 maio 2017.

STATISTA. Leading countries based on number of Facebook users as of april 2017 (in millions). [201-]. Disponível em: <www.statista.com/statistics/268136>. Acesso: 10 abr. 2017.

UNIMED. Viver bem: a nova relação entre o Dr. Google, o médico e o paciente. Cataguases -MG, 2014. Disponível em: <https://www.unimed.coop.br/web/cataguases/viver-bem/saude-em -pauta/a-nova-relacao-entre-o-dr-google-o-medico-e-o-paciente>. Acesso em: 13 jan. 2014.

VIEIRA, D. A. dos S. et al. Qualidade nutricional dos padrões alimentares de crianças: existem diferenças dentro e fora da escola? J. Pediatr. (Rio J.), Porto Alegre, v. 93, n. 1, p. 47-57, jan./fev. 2017. Disponível em: <http://www.scielo.br/scielo.php?pid=S0021-75572017000100047\&script=sci_arttext\&tlng=pt>. Acesso em: 29 maio 2017.

WEFFORT, V. R. S. et al. A alimentação complementar e o método BLW (Baby-Led Weaning). Guia Prático de Atualização, n. 3, maio 2017.

WEFFORT, V. R. S. (Org.). et al. Manual de orientação para a alimentação do lactente, do pré -escolar, do escolar, do adolescente e na escola. 3. ed. Rio de Janeiro: SBP, 2012. 